\title{
Effect of Mesoscale Eddy Dynamics on Bioproductivity of the Marine Ecosystems (Review)
}

\author{
A. S. Mikaelyan ${ }^{1}$, A. G. Zatsepin ${ }^{1}$, A. A. Kubryakov ${ }^{2} \bowtie$ \\ ${ }^{1}$ Shirshov Institute of Oceanology, Russian Academy of Sciences, Moscow, Russian Federation \\ ${ }^{2}$ Marine Hydrophysical Institute of RAS, Sevastopol, Russian Federation \\ $\bowtie$ arskubr@ya.ru
}

Different types of mesoscale eddy dynamics are considered in the paper from the viewpoint of their effect on the plankton (mainly phytoplankton) amount and its taxonomic structure. The eddy structures of all types, including cyclonic, anticyclonic, water-body anticyclonic and frontal ones, as well as the dipole structures, actively affect plankton. Theoretical schemes of the influencing mechanisms, which are illustrated by the examples of such an impact on the plankton in the Black Sea, are examined. The analyzed responses of the marine plankton ecosystems to the eddy dynamics and the scientific literature review unambiguously testify the important role of these processes in formation of biological productivity in the seas and oceans. A cyclonic eddy forms the isopycnals rise (a dome-like bend) in its core both in the thermocline and in the pycno-halocline that elevates nitrocline; it promotes bioproductivity increase. In the center of the anticyclonic eddy, the thermocline and pycno-halocline deepen (deflection) which negatively affects bioproductivity. At the same time, the rise of the isopycnals occurs at the eddy periphery that, on the contrary, contributes to increase in primary production. In contrast to a regular anticyclone, a water-body (or lens-like) eddy induces the water rise in a layer above the depth of the maximum orbital velocity of the eddy, in other words, in its upper part it often acts like a cyclone. Thus, in any eddy there are the areas where the thermocline rises to the surface and, therefore, the prerequisites for the bioproductivity increase are formed. Strong winds not only enhance the effect of the eddies on biota, but can completely change the nature of this impact. When exposed to wind, the intensity of the biogenic elements transport to the photic layer in the cyclones can decrease, whereas in the lens-like anticyclones it can increase. The important point is that the long-living eddies change the influencing mechanisms depending on the stage of their evolution. At last, the eddy structures often promote changing in the dominant phytoplankton species that can significantly alter the flow of organic matter to the bottom and affect the global carbon cycle.

Keywords: mesoscale eddies, phytoplankton, chlorophyll- $a$ concentration, coccolithophores, nutrient fluxes, horizontal exchange, vertical exchange, Black Sea

Acknowledgements: the investigation was carried out within the framework of the theme of state task No. 0149-2019-0010 at financial support of the RSF grant No. 20-17-00167. The eddy dynamics affect on the phytoplankton vertical structure was analyzed at support of the RFBR grant No. 20-0500068. Influence of sub-mesoscale eddies upon the shelf water transfer was analyzed using the satellite data at support of the RFBR grant No. 19-05-00479.

For citation: Mikaelyan, A.S., Zatsepin, A.G. and Kubryakov, A.A., 2020. Effect of Mesoscale Eddy Dynamics on Bioproductivity of the Marine Ecosystems (Review). Physical Oceanography, [e-journal] 27(6), pp. 590-618. doi:10.22449/1573-160X-2020-6-590-618

DOI: $10.22449 / 1573-160 X-2020-6-590-618$

(C) A. S. Mikaelyan, A. G. Zatsepin, A. A. Kubryakov, 2020

(C) Physical Oceanography, 2020

\section{Introduction}

Numerous studies considering the effects of physical processes on phytoplankton at the mesoscale and sub-mesoscale levels and on the synoptic time scale in a first approximation can be divided into several directions. Most of 
the works are devoted to the influence of mesoscale cyclonic and anticyclonic eddies. Canonical theory assumes vertical rise of isopycnals in cyclonic eddies (the so-called eddy pumping), leading to an increase in the nutrient flow into the photic zone [1]. In dipole structures, the rise of deep waters in a cyclonic eddy is accompanied by the sinking of waters in the adjacent anticyclonic eddy [2]. Accordingly, in the first case, there is an increase in biological production and in the second one - a decrease.

Except the aforementioned ones, there are many features of the effect of eddies on the ecosystem, associated with specific types of eddies and their parameters, as well as their interaction with other dynamic structures and the presence of atmospheric effects. So, among anticyclonic eddies, there is a special type a mode-water or lens-shaped eddy. The orbital speed in it is maximum at a certain depth, leading to the formation of an intra-water anticyclonic lens and the rise of isopycnals to the surface [3].

Frontal eddies, i.e. eddies located on the border with another water mass, should be distinguished. These eddies, formed in the baroclinic flow meanders, have a complex constitution and often represent a dipole structure. Theoretical scheme of such a structure has recently been demonstrated on the example of a coastal frontal current in the Western Mediterranean [4]. If the geostrophic velocity of water rise in a cyclonic eddy was about $1 \mathrm{~m} \cdot \mathrm{day}^{-1}$, then in the frontal zone between the cyclonic and anticyclonic eddies it was estimated at $10-100 \mathrm{~m} \cdot \mathrm{day}^{-1}$ from the anticyclonic eddy side.

In the shelf and slope zones, sub-mesoscale processes are of great importance. Their dynamics is determined by strong vorticity and high deformation rates that occur on a scale of $0.1-10.0 \mathrm{~km}$ [5-7]. They can generate vertical velocities up to $100 \mathrm{~m} \cdot \mathrm{day}^{-1}$ and play a decisive role in the transport of biogenic elements to the photic zone.

Three main mechanisms of eddy impact on phytoplankton and primary production are considered in the literature: transport of biogenic elements into the photic zone [4], the entry of a part of the depth maximum of biogenic elements into the photic zone due to the rise of isopycnals to the surface [8], and horizontal advection of shelf waters richer in phytoplankton (biogenic elements) in anticyclonic eddies [9-11]. The phytoplankton biomass increase in a separate cyclonic eddy is described in several works. The development of diatoms and a shift in the phytoplankton composition size towards a larger fraction can be observed both in the upper layer due to an increase in the flow of biogenic elements, and at depth, at the photic zone boundary, as a result of the rise of nitrocline to the surface $[8,12,13]$. The eddies generated by the meandering flow and/or interacting with each other are complex systems with a great heterogeneity of hydrophysical and hydrochemical conditions. In the case of the shelf-slope sea area, they can also be accompanied by local upwellings $[14,15]$.

In addition, the impact of eddies on the phytoplankton development is largely determined by the wind regime [5]. Under the Ekman pumping effect, water 
upwelling and phytoplankton growth can occur on one side of the anticyclonic eddy, while on the other hand, water sinking and zooplankton accumulation can take place [3]. The formation of water upwelling zones at the anticyclonic eddy periphery in combination with the wind effect leads to an increase in the nutrient flux into the photic layer, resulting in phytoplankton development along the eddy perimeter [16].

Finally, the eddy lifetime is of fundamental importance. In short-lived eddies (with a lifetime of a few weeks), the species structure of phytoplankton does not change, only its amount varies [17]. In long-lived (months) eddies, the species structure and biodiversity of phyto- and zooplankton change [18-20].

All these processes can act both separately from each other and simultaneously, generating different environmental conditions and in each specific case, accordingly, a different response of plankton. To understand which of these processes is responsible for the planktonic algae development, in what situations and how it affects the heterotrophic components of plankton is an urgent task of contemporary research in this field.

The importance of the scientific task is determined by the large role of mesoscale and submesoscale dynamics in the creation of primary production. About half of the primary production on Earth is created in the surface ocean layer (mainly by phytoplankton) [21]. Field studies and model calculations indicate that, in many cases, the intensity of this process is determined by physical impact precisely at the mesoscale level. Despite the relatively low values of the vertical velocity, the annual flux of biogenic elements in mesoscale eddies can be quite significant, especially in the oligotrophic areas of the World Ocean. For example, in the northern part of the Sargasso Sea, their total flux into the upper photic layer during winter convection is comparable to the total flux created by mesoscale eddies during the rest of the year [22].

In the present paper various types of mesoscale dynamics and their impact on plankton in the Black Sea are considered. The long history of studies of the Black Sea mesoscale eddies (see, for example, [23-27]), a large array of field data available and remote sensing allow example-illustration of various options for the effects of eddies that similarly "operate” throughout the World Ocean. It should also be noted that there is a tendency for the intensification of large-scale and weakening of synoptic dynamics of waters in the area [28]. Therefore, studies of the influence of dynamic processes on the sea ecosystem are necessary, including for predicting the ecosystem response to long-term climate change.

\section{Various types of eddy dynamics and their effects on marine plankton}

Among the variety of physical mechanisms of eddy impact on marine plankton, several of the most common ones can be distinguished. One of the most widespread methods for studying these mechanisms is the analysis of bio-optical parameters using satellite measurements [9, 11, 29-32]. 
For figures in this article, MODIS-Aqua satellite scanner images (L2, $1 \mathrm{~km}$ resolution) were used, showing the distribution of chlorophyll a (Chl) concentration in the surface layer. In addition, images of the remote sensing reflectance at a wavelength of $555 \mathrm{~nm}(R R S)$ were analyzed. A sharp increase in RRS in the central sea part is a good indicator of a high concentration of coccolithophores [33, 34]. The data was downloaded from the archives of https://oceancolor.gsfc.nasa.gov/.

To describe the dynamic characteristics of eddies, a daily array of mapped altimetry data on geostrophic current velocities with $0.125^{\circ}$ resolution was used. The array was obtained on the basis of the regional array of Black Sea level anomalies (from the Copernicus Marine Environment Monitoring Service archive) and the average dynamic topography [35]. A detailed description and validation of the array were made earlier in [11].

Mesoscale baroclinic eddies and eddy structures, discussed in this paper, can be divided into several types according to their effect on bioproductivity. First, there are classical cyclonic and anticyclonic quasi-isolated eddies with a diameter of $40-100 \mathrm{~km}$ and having a maximum orbital velocity on the sea surface. Their sizes are comparable to the Rossby baroclinic deformation radius, which is $15-25 \mathrm{~km}$ [36, 37]. The main mechanism for the formation of these eddies is apparently the baroclinic instability of the Black Sea Rim Current [38, 39]. The concentration of eddy energy is maximum in the Rim Current action area [27] with the core located above the continental slope of the Black Sea [36]. The largest, or recurrent, anticyclones - the Batumi and Sevastopol ones - can be formed under the influence of direct anticyclonic vorticity of wind stress friction [26, 40]. In addition, an important source of potential eddy energy is the desalinated shelf waters, entering the central part of the basin when the Ekman pumping is weakened. Shear, or barotropic, instability of current (especially in the cold season) can make a significant contribution to the cyclonic eddies' formation [38, 39].

Eddy motion, as a rule, penetrates to a depth up to $200 \mathrm{~m}$, and in large eddies up to 500-1000 m [23, 32, 41-43]. The eddy lifetimes range from several weeks to one year. Anticyclonic eddies are on average larger than cyclonic ones and exist for a longer time [27]. In the warm period of the year, more anticyclonic eddies are observed, in the cold - more cyclonic ones [38, 39].

In addition to classical anticyclones in the Black Sea, there are many anticyclonic eddies, having their maximum orbital velocity not on the sea surface, but in the cold intermediate layer, at a depth of 30-60 m [38]. Such eddies are called lens-like. In contrast to eddy lenses [44], which are located in the main pycnocline area, the maximum orbital velocity of lens-like eddies is located above it, in the intermediate water layer formed during winter convective mixing [45]. Eddies of this kind are found in various regions of the World Ocean, in particular, in the Sargasso Sea [46]. 

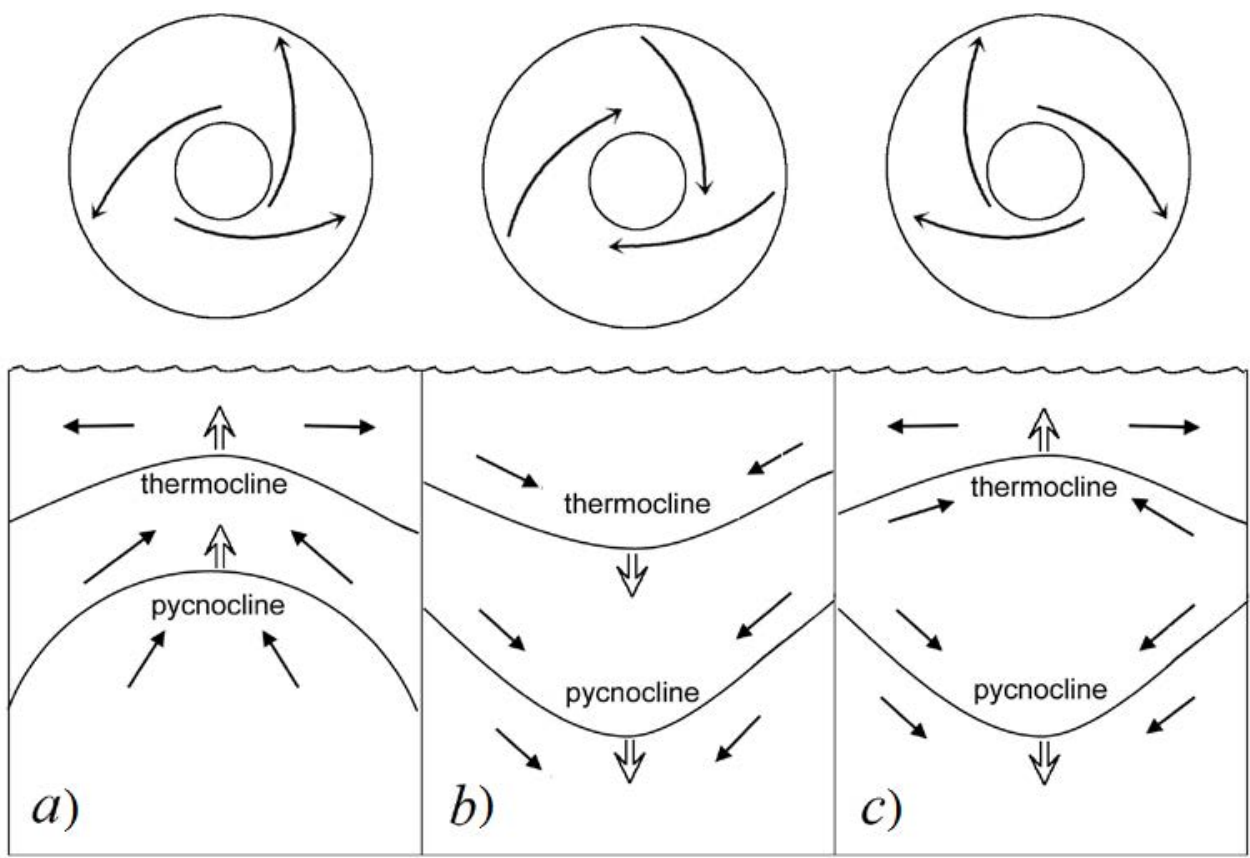

Cyclone

Anticyclone

Lens-like anticyclone

F i g. 1. Scheme of vertical deformations of the seasonal thermocline and the main pycno-halocline under the influence of eddies of various types: $a$ - cyclone, $b$ - anticyclone, c - lens-like anticyclone. Black arrows show the direction of water movement in different layers under the influence of poloidal circulation in the eddy; hollow arrows - direction of movement of the gradient layers. The upper part of the scheme shows direction of the currents on the surface. The diagram is valid for the intensifying eddies. For the weakening eddies, the movement direction is reversed

It is difficult to say whether the formation mechanisms of anticyclonic lenslike eddies and classical anticyclones in the Black Sea differ. Most likely, both types of anticyclones, as a rule, are formed from the Rim Current meanders during the current instability development. Obviously, in the winter and early spring seasons, when there is no thermocline and the Rim Current is well developed [47], classical anticyclones should form. In the summer and autumn seasons, when there is a thermocline separating the upper layer from the cold intermediate layer (CIL), wind action and thermohaline gradients can weaken the water dynamics in the upper mixed layer (UML), but in CIL it does not experience such influences. Perhaps that is why most anticyclones in the summer-autumn period are lens-like eddies. This hypothesis needs to be tested.

Eddies of various types cause different deformations of the thermocline and the main pycno-halocline (Fig. 1). The cyclonic eddy creates a rise (dome-like bend) of the isopyclinals in its core in both the thermocline and the pycno-halocline (Fig. 1, a). As a result, nitrocline, associated with the density structure of the waters in the Black Sea, rises in cyclones closer to the sea surface, which can contribute to an increase in bioproductivity. In turn, there is a lowering (deflection) of the thermocline and pycno-halocline (Fig. 1, $b$ ) in the anticyclonic eddy core, which, as a rule, negatively affects the bioproductivity. In this case, the rise of 594

PHYSICAL OCEANOGRAPHY VOL. 27 ISS. 6 (2020) 
isopycnals occurs at the eddy periphery (Fig. 1, b), on the contrary, contributing to an increase in the primary production in the UML. In contrast to a standard anticyclone, a lens-like eddy creates the water upwelling above the depth of maximum velocity of water flow and its downwelling below this depth (Fig. 1, c). Accordingly, the thermocline in a lens-like eddy rises as in a cyclonic eddy, and a pycno-halocline deepens as in an anticyclonic eddy [46]. Thus, in any eddy there are areas where the thermocline rises to the surface (Fig. 1) and, therefore, the prerequisites are created for bioproductivity increase. Note that in the Black Sea, the vertical displacements of the pycno-halocline in eddies can reach several tens of meters [23, 24, 32], and the thermocline - several times smaller values due to the fact that the density gradient in a developed thermocline is several times greater than in pycno-halocline, and it is more difficult to "bend" it [38]. All three types of eddies are characterized by different directions of currents in the surface layer (Fig. 1), which theoretically makes it possible to identify them on satellite images using tracers.

Cyclones and anticyclones in the Black Sea are often found not in a quasiisolated form, but in the form of eddy dipoles (eddy pairs) or multipoles [48]. In this case, anticyclones in an eddy pair can be classical or lens-like. As a result, in some eddy dipoles, a lowering of the thermocline in the anticyclone and its rise in the cyclone are observed, and in others, the rise of the thermocline in both eddies.
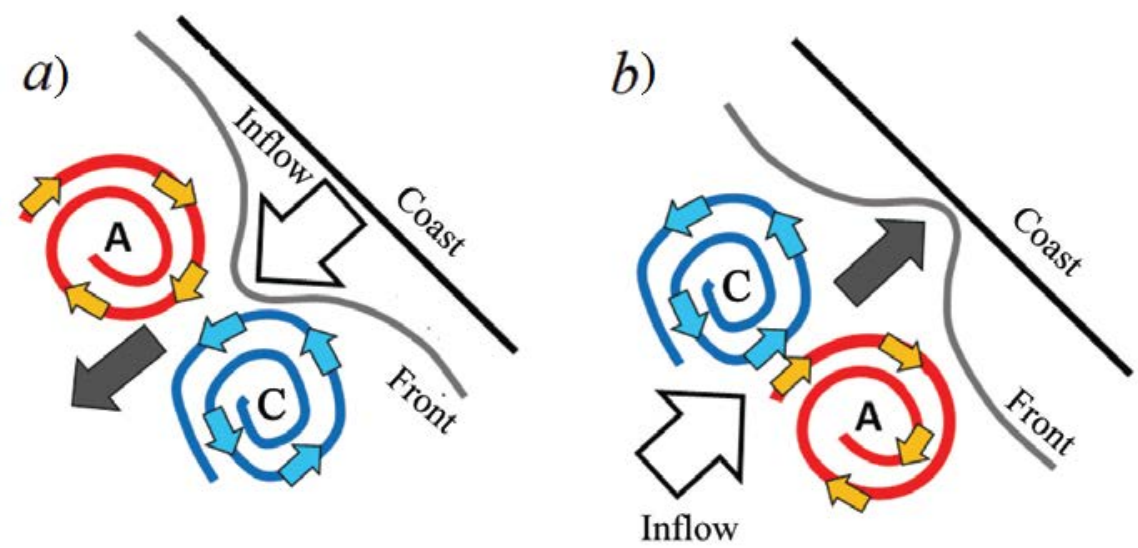

F i g. 2. Scheme of the eddy dipole and direction of its movement depending on location of the eddies of different signs in it: movement of the eddy dipole from the coast $(a)$, to the coast $(b)$. Black straight line - the coastline, gray curved line - the front between the coastal and the open waters; colored arrows - the direction of water rotation in the dipole eddies; gray arrows the direction of the eddy dipole motion; white arrows - the inflow of surrounding water to the eddy dipole leg; A - the anticyclonic eddy; $\mathrm{C}$ - the cyclonic eddy in the dipole

Dipole eddy structures are capable to move rapidly horizontally due to the fact that each eddy "drags" its partner in its rotation direction in the area of the "eddy leg" of the dipole (Fig. 2). As a result, the eddy dipole formed in the Rim Current area can move to the deep-water sea part $[38,49]$ if the cyclone is located to the left and the anticyclone to the right in relation to the observer contemplating 
the sea from the coast (Fig. 2, a). With the opposite arrangement of the eddies in the pair, it will move towards the coast, pressing against the upper part of the continental slope (Fig. 2, $b$ ). In dipoles and multipoles, eddies can exchange both substance and momentum with each other. In addition, water adjacent to them can enter these eddies through the "eddy legs", increasing the water exchange of dipoles and multipoles with the environment compared to quasi-isolated eddies separated from the adjacent waters by frontal sections.

An important property of all eddies is the ability to involve the surrounding waters in their movement and "wind them on themselves" on the eddy periphery. This greatly contributes to horizontal water exchange, the transfer of waters from the shelf to the open sea and vice versa [9, 11, 25, 30, 49 and 50]. Eddy water exchange associated with both orbital and translational motion produces cross-shelf exchange in the basin and promotes the homogenization of the Black Sea waters in the upper layer and along the isopycnals [37].

In the following sections below, the examples of various types of eddies and eddy structures, their influence on the distribution of chlorophyll $a$ and suspended matter of a different nature in the Black Sea will be considered, and a literature review of their effect on biota in the World Ocean will be presented.

\section{1. Open sea eddies}

\section{Cyclonic eddies}

In closed seas, such as the Black Sea, cyclonic eddies not associated with alongshore currents are rare. Being in relatively poor waters, the cyclonic eddy significantly increases biological productivity. In October 2017, such an eddy caused an increase of $\mathrm{Chl}$ in the surface layer (Fig. 3). Field observations showed that this was associated with the development of the large diatom Pseudosolenia calcar-avis [17]. It should be noted that the mechanisms of the cyclonic eddy effect on the biota can be different in the surface and deep layers. In the given example, the increased inflow of nutrients into the UML led to the development of large diatoms. At the same time, the rise of the upper part of the CIL above the level of $1 \%$ of photosynthetic active radiation from the surface one led to the formation of a powerful depth Chl maximum, formed by small nanoflagellates and cyanobacteria.
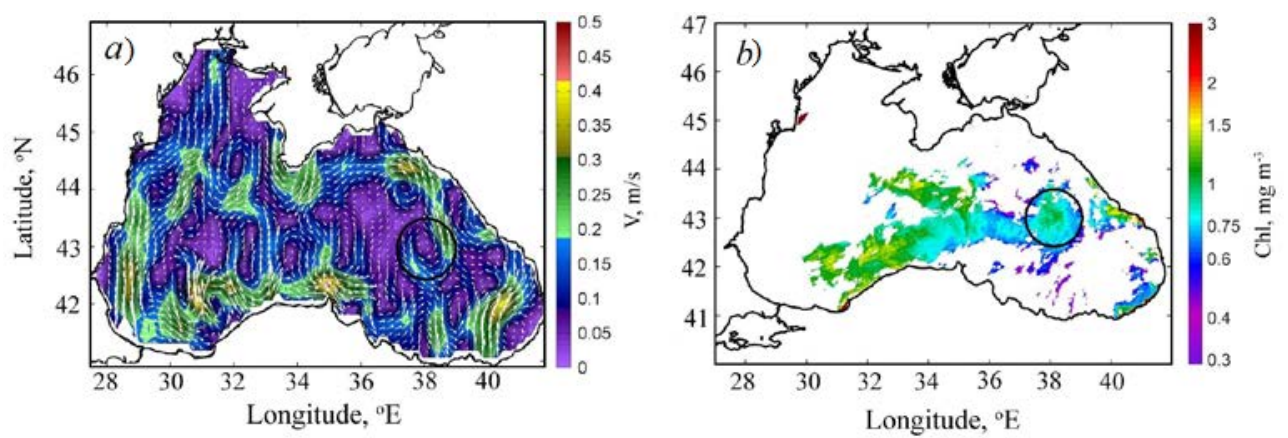

F i g. 3. Influence of the cyclone on phytoplankton on October 27, 2017: $a$ - the geostrophic field of the surface current velocity (V), and $b$ - distribution of the chlorophyll $a$ concentration $(C h l)$. The circle indicates the cyclonic circulation location 
Examples of the positive impact of cyclonic eddies on the level of quantitative development of phytoplankton are numerous throughout the World Ocean. Increased Chl values in such eddies were recorded in the South China Sea [51]. In the same area, Chl and the primary production in a cyclonic eddy were 3-35 times higher than those in the surrounding waters [52]. The eddy was dominated by diatoms and unicellular cyanobacteria, while filamentous cyanobacteria, typical of oligotrophic waters, predominated in the surrounding waters. In the subtropical Pacific, cyclonic eddies markedly increased the primary production [1]. In subtropical waters off the Hawaiian Islands, increased Chl and the growth rate of algae were observed in the cyclone, and the share of production created due to the inflow of new nutrients increased from 0.2 to 0.8 [53]. In another cyclone in the same area, not only increased $C h l$ values, but also differences in the taxonomic composition of phytoplankton were observed [54]. In the eddy, the depth maximum of Chl was more powerful and located shallower than in the surrounding waters. Small eukaryotes developed inside the eddy, and prokaryotic picophytoplankton predominated in the surrounding waters. In the subtropical waters of the North Atlantic, a cyclonic eddy caused the unicellular cyanobacteria development at a depth [55]. In 2005, a powerful cyclonic eddy developed in the area of the Hawaiian Islands, but in this case, the rise of the deep Chl maximum led to the bloom of large diatoms Rhizosolenia and Chaetoceros instead of cyanobacteria dominating in the surrounding waters [56]. In the same area of the oligotrophic Pacific, the rise of isopycnals in the cyclonic eddy led to the appearance of a Chl maximum at a depth of $30 \mathrm{~m}$, formed by prochlorophytes , chrysophytesand small green algae [57]. The reasons for such a different response of the taxonomic structure of phytoplankton to the impact of cyclonic eddies in the same ocean region are unclear [2].

The factors determining the dominance of species as a result of eddy action have poorly been studied. Here work [58] is to be referred. It shows that the reaction of diatoms to eddy upwelling in subtropical regions depends on the ratio of nitrate and silicate in water. In the Pacific Ocean (Hawaii), in the intermediate layer, a relatively high concentration of silicate led to the development of diatoms, while in the subtropical Sargasso Sea, against the background of the rise of silicate-poor water, picophytoplankton developed.

\section{Anticyclonic and lens-like eddies}

Classical influence on the distribution of biological objects was demonstrated by three anticyclonic gyres AC1, AC2 and AC3, which were simultaneously present in the Black Sea in June 2003 (Fig. 4). In their nuclei, Chl was lower than in the periphery. In anticyclones, the vertical velocity is directed downward, which leads to the lowering of the nitrocline and prevents the flow of nutrients into the photic layer. Therefore, the cores of anticyclones should have lower primary production and lower $C h l$, which is often observed in reality. 

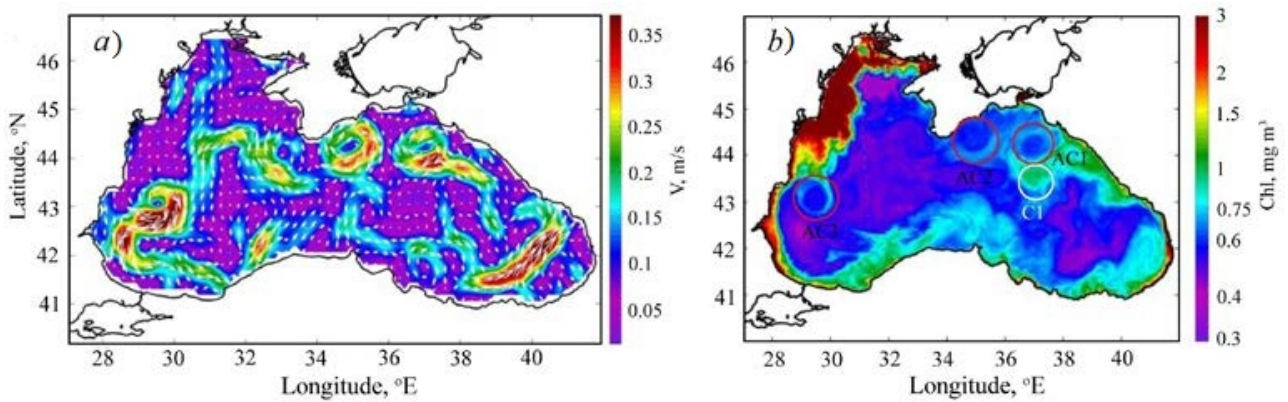

F i g. 4. Series of anticyclones on June 17, 2003: $a$ - the geostrophic field of the surface current velocity (V); $b-\mathrm{Chl}$ distribution under the influence of a cyclonic eddy (C1) and anticyclonic eddies (AC1, AC2 and AC3). The circles indicate locations of the eddies

The largest and longest-lived anticyclone in the Black Sea is the so-called Batumi eddy. It strongly deepens the isopycnals in its core, which leads to a decrease in the flow of new nutrients into the photic layer. At the same time, the increased UML thickness leads to a decrease in the average irradiance in this layer. This is especially important for such a group of algae as coccolithophores, which usually develop at high light level. As a result, during the period of dominance of these algae in phytoplankton (May - June), the growth of phytoplankton in the eddy significantly slows down and biological production inside it turns out to be much lower than in the surrounding waters (Fig. 5). Note that this process is characteristic of a certain stage of the eddy development, which will be considered in more detail below.
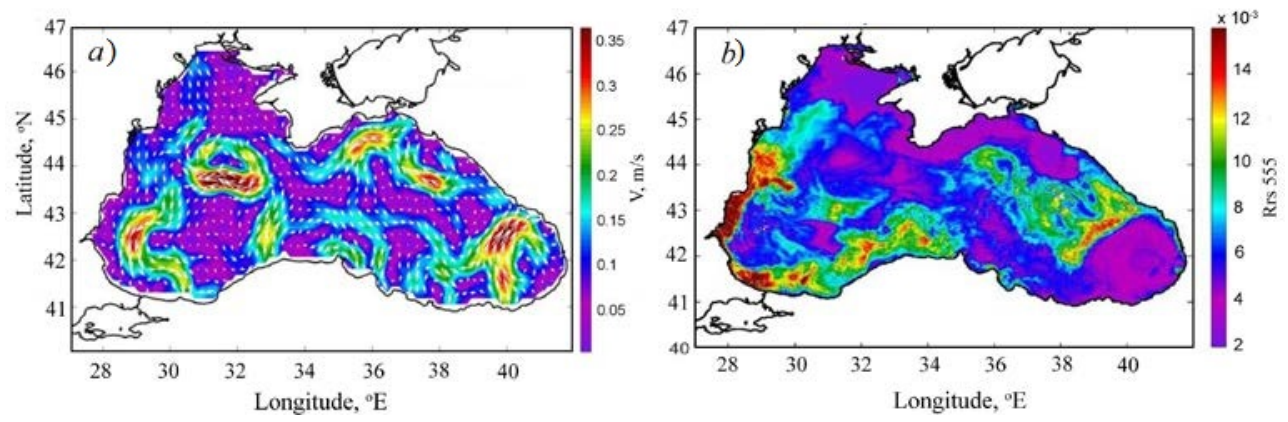

F i g. 5. The Batumi eddy on June 6, 2008: $a$ - geostrophic field of the surface current velocity (V); $b$ - spatial distribution of RRS at the wavelength $555 \mathrm{~nm}$ (reflectance indicates intensity of coccolithophore bloom)

However, based on the example above (Fig. 5) it cannot be concluded that regular anticyclones "work" only for Chl lowering in the near-surface layer. Fig. 4 shows that increased $\mathrm{Chl}$ is manifested at the periphery of all three anticyclonic gyres - AC1, AC2 and AC3. At the same time, AC3 clearly involves and extends along its periphery the chlorophyll-rich waters of the northwestern shelf of the Black Sea. This mechanism, described earlier in [9, 11, 30, 49, 59 and 60], is very important for water exchange between the shelf and the deep sea and will be separately considered below. 
According to hydrological survey data, many mesoscale anticyclonic eddies in the Black Sea have a lens-like structure [24, 59]. In these eddies, the orbital velocity reaches a maximum in the CIL at a depth of $25-50 \mathrm{~m}$, as a result of which the seasonal thermocline rises upward and the main pycno-halocline descends downward (see diagram in Fig. 1,b). Thermocline rise is accompanied by the sea temperature decrease in the near-surface layer.

An example of the surface manifestation of such a lens-like anticyclonic eddy is shown in Fig. 6, $a$. It shows a satellite image of the surface temperature field from October 25, 1999, with the route of $\mathrm{R} / \mathrm{V}$ Akvanavt and the position of the stations with CTD-soundings plotted on it. The eddy core appears in this image as a dark spot of low temperature. According to the measurements with a towed thermal sensor (Fig. 6, b), it was lower $13{ }^{\circ} \mathrm{C}$, while outside the anticyclone in the north - over $14{ }^{\circ} \mathrm{C}$ and in the southwest - over $15^{\circ} \mathrm{C}$. The cold core of the eddy was separated from the surrounding waters by sharp fronts. In this case, the maximum of the orbital velocity in the eddy was located directly under the seasonal thermocline at a depth of $30 \mathrm{~m}$.
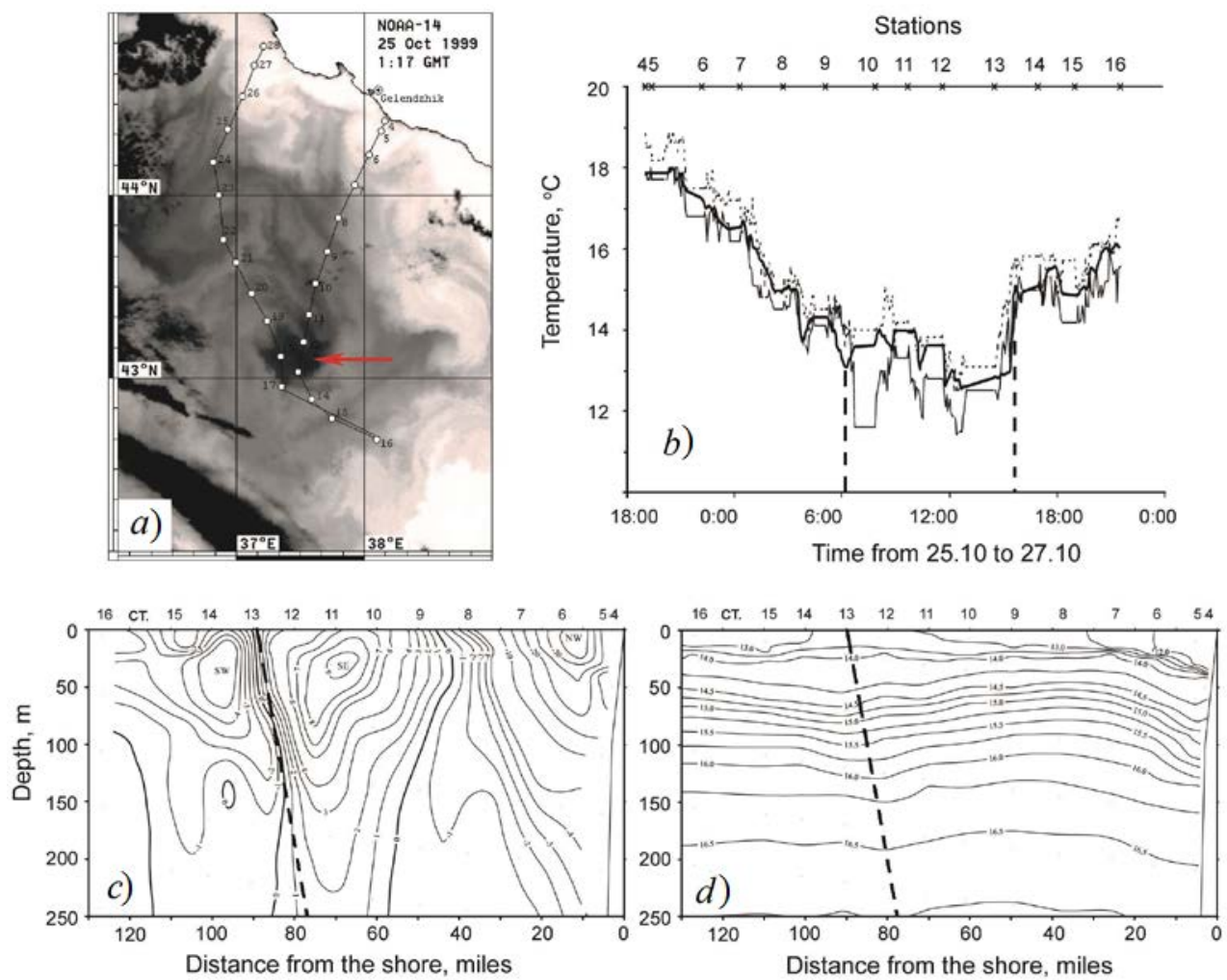

F i g. 6. The example of a lens-like anticyclone: $a$ - surface temperature field including the plotted route of the R/V "Akvanavt" in October, 1999 (red arrow indicates the cold spot above the eddy dome); $b$ - change of surface temperature based on the data of the towed thermal sensor (thick line), and from the satellite night-time (thin line) and day-time (thin dashed line) observations at the section across the eddy; $c$ - vertical distribution of the geostrophic current velocity $(\mathrm{m} / \mathrm{s}) ; d$ - water densities (sigma-t) at the transect across the anticyclonic lens-like eddy. Dash lines on panels c) and d) indicate a front between the cyclone and anticyclone 
The temperature decrease in the anticyclone center was caused by the rise of isotherms (isohalines, isopycnals) in the upper, approximately 20-m layer and their pinching out on the surface when lowering in the underlying layer (Fig. 6, $c, 6, d$ ). Obviously, in the autumn season, the most rapid cooling and destruction of the seasonal thermocline occurs above the upper domes of the lens-like anticyclones. This process should be accompanied by an increase in the flow of nutrients into the upper layer and an increase in biomass, which was confirmed in the case of A1 [18, 19].

It should be noted that eddy of this type affects the biota in different ways, depending on the stage of development [3]. At the stage of activation, it acts like a cyclonic eddy and at the stage of relaxation - like an ordinary anticyclonic eddy. Therefore, sometimes in the centers of lens-like anticyclonic eddies, increased concentrations of phytoplankton are recorded, and sometimes, on the contrary, oligotrophic conditions are formed [61]. In the example shown in Fig. 7 in the center of the quasi-stationary Batumi anticyclonic eddy in August 2008, a bloom of coccolithophores was observed. This phenomenon is well explained by the assumption about the lens-like structure of this eddy. In this case, the rise of isopycnals in its center reduces the UML thickness, which leads to the increase of an average irradiance in this layer, being in turn a powerful stimulating factor for the development and predominance of coccolithophores in phytoplankton, having a competitive advantage at high light conditions [17]. However, this impact is temporary. Nutrients are depleted, causing a decrease in the rate of algae growth and biological production.During attenuation stage, the effect of the eddy is the same as that of a conventional anticyclone. The temporal dynamics of coccolithophore bloom in the Batumi eddy, associated with a change in its activity, will be considered in more detail below.

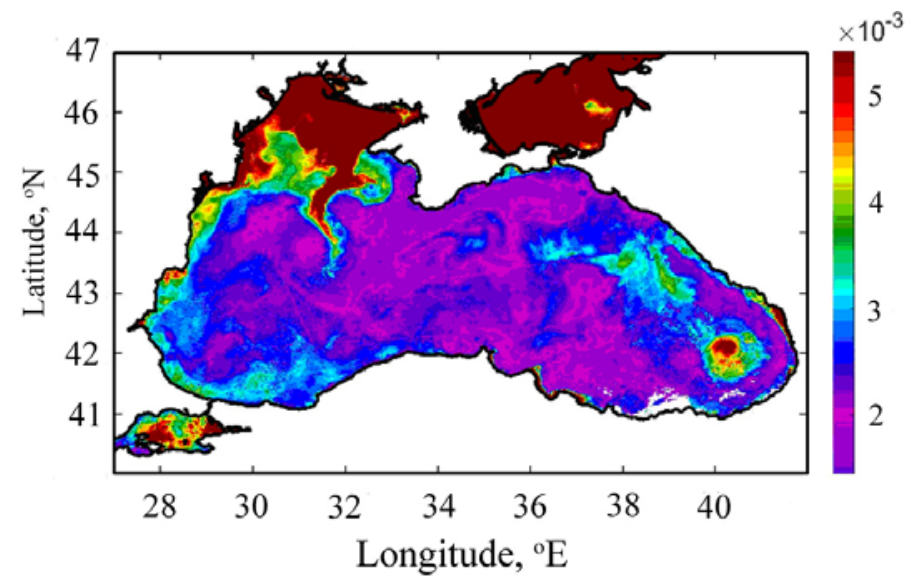

F i g. 7. Coccolithophore bloom (image of $R R S$ ) in the center of the Batumi anticyclonic eddy on July 9, 2008

The impact of lens-like eddies can be very powerful and even exceed the impact of cyclonic ones. In the Subtropical Atlantic in the center of such an anticyclone, a powerful deep bloom of diatoms Chaetoceros spp. [55] was formed. Chl reached a record value for this region of $1.4 \mu \mathrm{g} \cdot \mathrm{l}^{-1}$ and significantly 600

PHYSICAL OCEANOGRAPHY VOL. 27 ISS. 6 (2020) 
exceeded the slightly increased $\mathrm{Chl}$ in the neighboring cyclonic eddy. In the Bay of Biscay, in the lens-like eddy center, Chl was twice as high as at the edges of the eddy and in the surrounding waters [62]. In the similar eddy, which separated from the East Australian Current, $\mathrm{Chl}$ in the center exceeded the values at its periphery by 1.5-2 times [63]. In the eddy center, the phytoplankton biomass was based on the diatom Nitzschia seriata, and on the periphery, dinoflagellates and nanophytoplankton were found.

It should be noted that, in lens-like eddies, significant differences in the taxonomic structure of plankton in the upper layer and in the lens can be expected, since at the top the water flow is directed to the eddy periphery, and in the lens, on the contrary, to the center (see Fig. 1,b). This can lead to mechanical accumulation of certain zooplankton species in the lens. For example, in such an anticyclonic eddy in the Black Sea, the composition and amount of zooplankton at the depth of the lens location was clearly different from those in the surrounding waters [18].

There is another mechanism for increasing biological productivity inherent in conventional anticyclones. The high $\mathrm{Chl}$ at the periphery of the anticyclonic eddies AC1 and AC2 (see Fig. 4, a), apparently, can be partially associated with the rise of the nitrocline near the outer boundaries of the anticyclones and the increased influx of biogenic elements into the photic layer. The same can be said about the seaward periphery of the Batumi eddy (see Fig. 5, a). In fact, the periphery of the anticyclone is a frontal zone characterized by pinching out of isopycnals to the sea surface and the presence of an intense shear current, where submesoscale cyclonic eddies are formed. In such structures the vertical velocity directed to the surface reaches very high values [7,64]. Sometimes this leads to an annular distribution of $\mathrm{Chl}$ on the eddy surface. For example, in the anticyclonic eddy to the west of the Brazilian Current, Chl was increased at the periphery in comparison with the core and surrounding waters [65]. The same situations were observed in other areas of the World Ocean [3], including Antarctica [16].

Since in the center of a common anticyclonic eddy the vertical flux into the photic zone is minimal, it is most likely that the plankton is in the last stages of succession with a predominance of the heterotrophic component. For example, in the area of the Canary Current a higher biomass and activity of heterotrophic bacterioplankton were noted in anticyclones in comparison with cyclones and surrounding waters [66].

\section{Eddy dipoles and multipoles}

Cyclonic eddies in the Black Sea often (especially in the warm season) occur in dipole or multipole structures where they are adjacent to an anticyclonic eddy $[38,48]$. An example of such a dipole eddy structure can be seen in Fig. 4. Here the cyclonic mesoscale eddy $\mathrm{C} 1$ is adjacent to the anticyclonic mesoscale eddy AC1. This eddy pair, possessing the property of self-propulsion [38, 48], moves from the coast to the open sea, clearly demonstrating the different effects of eddy dynamics on the $C h l$ distribution in the near-surface layer. In the $\mathrm{C} 1$ cyclone, $C h l$ is higher than in the surrounding waters, and in the AC1 anticyclone, it is less. In this PHYSICAL OCEANOGRAPHY VOL. 27 ISS. 6 (2020) 
case, $\mathrm{Chl}$ in the cyclone is more than twice as high as $\mathrm{Chl}$ in the anticyclone. The obvious reason is the multidirectional vertical movements of water in cyclones and anticyclones (Fig. 1), which causes differences in the power of nutrient fluxes into the photic layer and in the level of primary production.

In theory, dipoles suggest pronounced differences in the structure and biomass of plankton in its eddies (with a higher productivity in a cyclone). However, in the case of a lens-like anticyclonic eddy, the opposite picture can also be observed. It is not excluded that the atypical distribution of plankton in the dipole in the eastern part of the Indian Ocean may be related precisely to the lens-like anticyclone. [67]. In the anticyclone center diatoms prevailed in the deep phytoplankton maximum. Their growth was inhibited by heterotrophic dinoflagellates. At the same time, in the cyclonic eddy, the deep maximum was formed by picoplankton typical for oligotrophic waters, consumed mainly by ciliates. However, there are also directly opposite observations. For example, in the Black Sea in October 1999, in the eddy pair, neither the phytoplankton biomass nor its taxonomic composition differed in dipole eddies, but sharply contrasted with the surrounding waters [19].

\section{2. Eddies of meandering current or fronts}

Eddies formed at the boundary of two aquatic environments with different plankton content affect the biota through two mechanisms, conventionally designated as mixing [68] and capture. In the first case, an eddy carries part of the rich waters into the poor ones and vice versa [3]. In the second case, an eddy, having formed, for example, in waters rich in plankton, penetrates into poor waters. Of course, in any case, there is a mixing of waters. Anticyclonic eddies often detached from the front have a spiral shape and appear on the surface by alternating bands with high and low Chl (Fig. 8). This is typical for such eddies throughout the World Ocean, for example, in the Mediterranean [69].

The Chl distribution in such eddies shows a decreasing trend as we move from the periphery to the center. However, it is significant that although $\mathrm{Chl}$ in these anticyclones is lower than on their periphery, it is higher than in the surrounding waters and the central part of the basin (Fig. 8). This particularly is associated with the ability of anticyclones to accumulate both the shelf water plankton and nutrients, since their amount usually is significantly higher on the shelf. As a result, biological dynamics prevails over mechanical processes [70].

For example, in the Black Sea in summer at the fronts of eddy structures, according to optical data, an increased concentration of coccolithophores can be observed (Fig. 9). Moreover, the blooming area often occupies an intermediate position between the shelf zone and the central part of the sea. One of the possible mechanisms of this phenomenon is an increase in the stability of waters in the shelf-open sea junction zone, associated with the inflow of fresh waters of the shelf onto the saline waters of the central part. As a result, the UML decreases and the average irradiance in it increases, favoring the development of coccolithophores. Subsequently, the UML in the centers of eddies deepens, and the bloom is declining. 

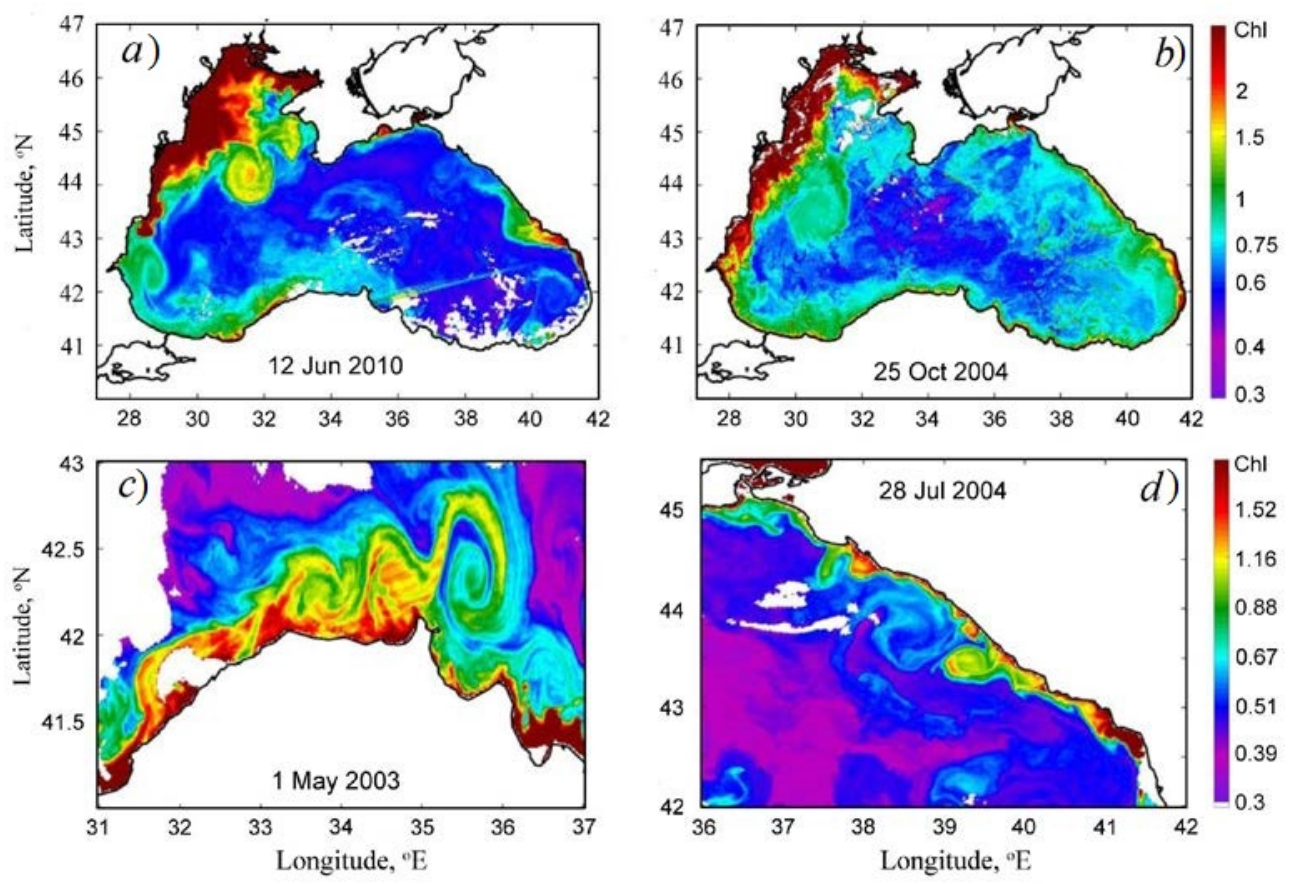

F i g. 8. Eddies of the frontal interfaces. Involvement of shelf waters in the orbital motions of the mesoscale and sub-mesoscale anticyclones manifested in the distribution of the chlorophyll $a$ concentration $\left(\mathrm{mg} / \mathrm{m}^{3}\right)$ : at the boundary of the northwestern shelf ( $a$ and $b$ ); nearby the Turkish shelf $(c)$; near the North Caucasus $(d)$

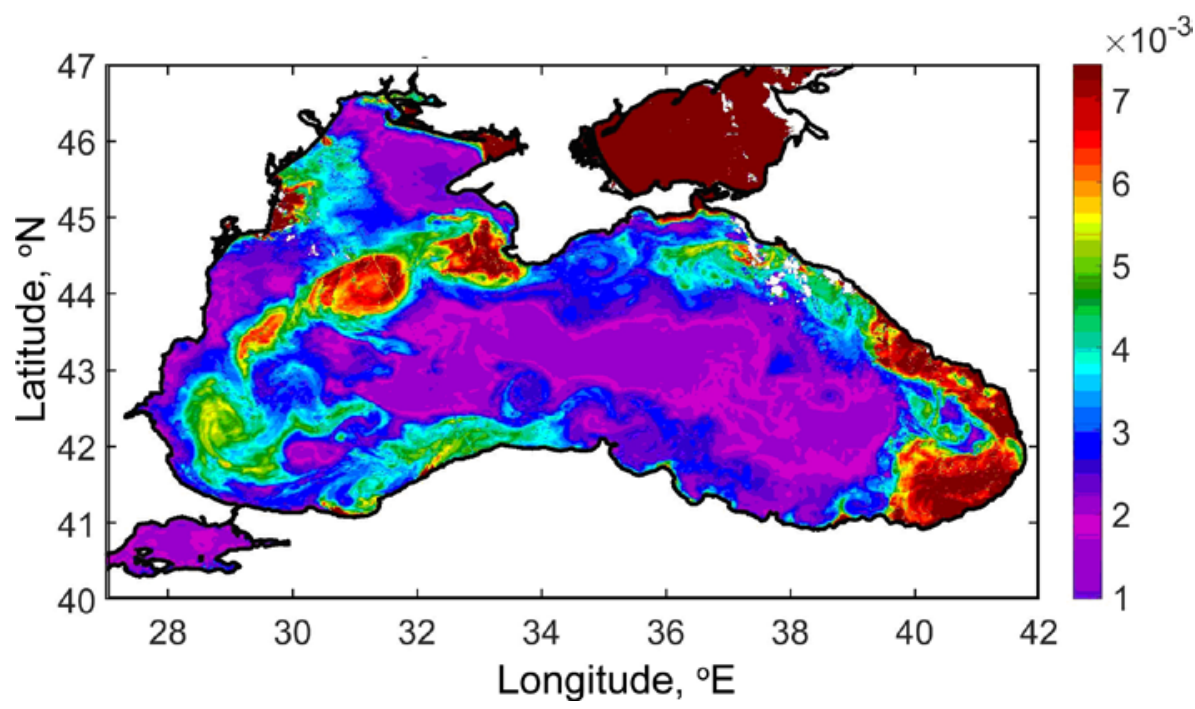

F i g. 9. RRS map for April, 2016 showing the features of the coccolithophore spatial distribution resulted from the affect of the anticyclonic frontal eddies

The impact of frontal eddies on the biota largely depends on their origin and age. The species structure of phytoplankton can persist for a long time in anticyclonic eddies separated from another water mass. In the South China Sea, 
cyanobacteria predominated in the anticyclonic eddy separated from the Kuroshio Current, while coccolithophores dominated in the eddy that formed in the north of the South China Sea [71]. Off the coast of Western Australia, the species structure of phytoplankton in the long-lived (five months) anticyclonic eddy corresponded to the coastal structure [10]. In the Gulf of Alaska, anticyclonic eddies formed on the shelf carried shelf phytoplankton and zooplankton into deep-sea waters [72]. At the same time, neritic and shelf phytoplankton species formed the basis of the community for several months. The trace amounts of shelf zooplankton species were observed even after a year of the eddy existence [73].

\section{3. Eddies under the wind impact}

In the surface layers of the Black Sea, in the warm season, a relatively thin UML is formed. It has few nutrients and Chl.. Satellite measurements record a seasonal $C h l$ minimum at this period. This is partly due to the low nutrient content and partly to photoacclimation processes, as a result of which the cellular content of chlorophyll $a$ is minimal. In this regard, the effect of eddy dynamics on biota is weakly manifested on the sea surface.

At the same time, a relatively high concentration of nutrients remains in the seasonal thermocline and below it. This allows deep phytoplankton to develop which is often manifested in the deep maximum of Chl. Because of these features of the vertical distribution, the effect of eddy dynamics is manifested on the surface after intense storms or abrupt cooling. These processes deepen the UML and lead to the involvement of nutrients and algae in it, in its turn, leading to an increase in $\mathrm{Chl}$ and to irregularities in its distribution, which can be seen on satellite images.
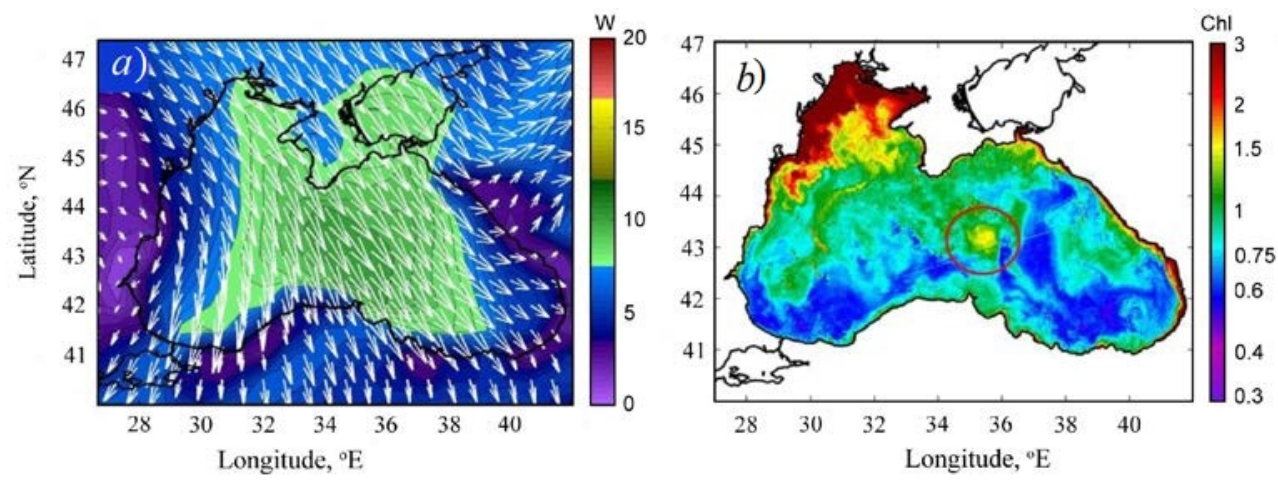

F i g. 10. Impact of strong wind on phytoplankton in the eastern Black Sea in September, 2009: $a-$ the wind speed map $(\mathrm{W}, \mathrm{m} / \mathrm{s}) ; b$ - the area of high chlorophyll $a$ concentration $(\mathrm{Chl}, \mu \mathrm{g} / \mathrm{l})$ in the cyclonic eddy (indicated by a circle)

The wind impact is most clearly manifested in the case of cyclonic eddies. In September 2007, a strong northwest wind was operating in the central Black Sea. As a result of wind mixing and seasonal thermocline exposure, an area with very high $C h l$ values (more than $1.5 \mathrm{mg} / \mathrm{m}^{3}$ ) appeared in the basin center (red circle 
in Fig. 10, b). The spatial distribution of Chl indicates that this region corresponds to the cyclonic eddy position. The thermocline and nitrocline rise in the cyclone and their erosion under the action of the storm led to an increase in Chl by more than two times in comparison with the surrounding waters.

Absence of such an effect and even the opposite decrease in Chl is shown in satellite images in anticyclones after partial destruction of the thermocline and upper layer homogenization. A striking manifestation of this effect was observed in August 2015. The action of four strong storms led to a powerful bloom of phytoplankton in the eastern Black Sea [60]. The maximum Chl was observed in the center of the eastern cyclonic gyre in the area of the nitrocline rise (Fig. 11). Repeated wind impact led to an intensification of cyclonic gyre and mixing, which caused further growth of algae in this area. At the same time, this effect could not stimulate the growth of algae in the A1 anticyclone, located near the southern coast of Crimea. This was probably due to the low content of phytoplankton and nutrients in it, which spread to great depths. In addition, nitrocline in anticyclones can descend by more than $50 \mathrm{~m}$ [32], which suppresses the vertical flow of nutrients. As a result, even with strong mixing of the UML, erosion of the deeply located nitrocline and phytoplankton bloom does not occur.
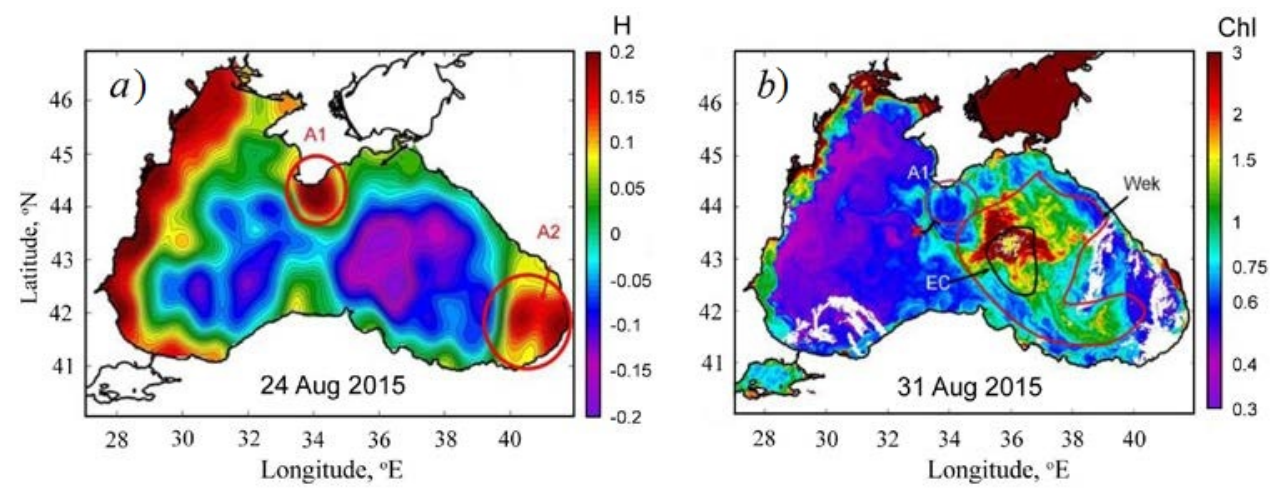

F i g. 11. Phytoplankton bloom after a series of storms in summer, 2015: $a$ - active cyclone in the center of the eastern part of the sea based on the altimetry data (H, $\mathrm{m}) ; b$ - increased chlorophyll $a$ concentration $(\mathrm{Chl}, \mu \mathrm{g} / \mathrm{l})$ in the cyclone zone after a week. Red contour indicates the region of the maximum Ekman pumping (Wek); black one - the location of the eastern cyclonic circulation (EC); circles - the Crimean (A1) and the Batumi (A2) anticyclones

A similar effect of bloom suppression in anticyclonic eddies can be observed in winter with characteristic strong winds. In January 2005, the winter bloom of coccolithophores developed in the eastern and western central parts of the sea (Fig. 12). However, there was no bloom to south of Crimea and the RRS values were five times lower than in the sea center. Altimetry data show that at that time there was a fairly intense anticyclone. Its round shape is clearly visible from optical data. The bloom suppression in it can be associated, as in the previous case, with 
the nitrocline lowering. Thermal convection does not reach it in winter and the flow of nutrients into the photic zone is minimal. Another additional reason may be deep UML. In winter, its formation in anticyclones is associated with the pycnocline deepening and the convergence of homogeneous waters in their cores [74]. As a result, the average irradiance in such the UML decreases and may be insufficient to compensate for cell losses for respiration, which almost stops the phytoplankton growth [75].
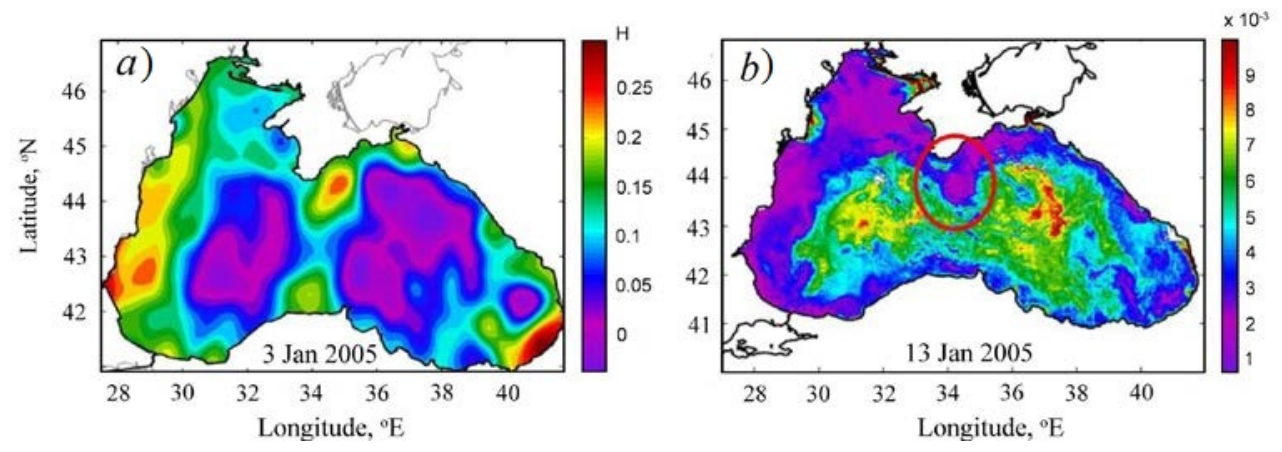

F i g. 12. Suppression of the coccolithophore bloom after the storms in January, 2005: $a-$ the anticyclone nearby the Crimea coast based on the altimetry data $(\mathrm{H}, \mathrm{m}) ; b$ - decrease in the coccolithophore concentration in the anticyclone (red oval) based on the RRS measurements

Strong winds not only enhance the effect of eddies on the biota, but can completely change its nature [3]. For example, in the Subtropical Atlantic, longterm measurements showed diatom blooms to be regularly observed in lens-like eddies [55]. A hypothesis was put forward, according to which, under the wind impact, in cyclones the rate of entry of nutrients into the photic layer decreases, and in lens-like anticyclones it increases. Model calculations and experiments with the $\mathrm{SF}_{6}$ tracer demonstrated that under wind action, the vertical velocities in the anticyclones were significantly higher than in the cyclones. This is particularly consistent with the development of diatoms in the center of an anticyclonic eddy (probably lens-like), separated from the Gulf Stream after the impact of the storm [76]. Presumably, anomalous phytoplankton bloom in the lens-like anticyclonic eddy in the North Atlantic was also a consequence of powerful Ekman pumping [77]. In the southern Indian Ocean, long-term satellite observations showed that in winter with characteristic strong winds the increased $\mathrm{Chl}$ was observed precisely in anticyclonic eddies [78].

\section{4. Long-living eddies and their impact on temporal dynamics of phytoplankton (by the example of the Batumi anticyclone)}

The temporal evolution of eddy and the change in the mechanisms of its impact on the biota are the key regulators of the biogeochemical processes [55]. In the Black Sea, temporal changes in the effect of the eddy on bioproductivity can be 606

PHYSICAL OCEANOGRAPHY VOL. 27 ISS. 6 (2020) 
traced using the example of the quasi-stationary Batumi anticyclonic eddy [36]. This structure has a diameter often exceeding $100 \mathrm{~km}$ and an orbital rotation velocity of up to $0.8 \mathrm{~m} / \mathrm{s}$ and even higher. Apparently, it can be both a classical anticyclone with a maximum velocity on the sea surface and a lens-like eddy with a maximum velocity below the seasonal thermocline. The main pycno-halocline in the core of this eddy descends by several tens of meters in comparison with the surrounding waters, and the CIL has the greatest thickness in the entire Black Sea [36]. The seasonal thermocline in this eddy can be deepened relative to the surrounding waters, if it has a classic appearance for an anticyclone, or raised if it has a lens-like structure.

On the basis of numerical modeling of the Black Sea circulation, it was shown that the baroclinic instability processes are very active in the area of the Batumi anticyclone [79]. These processes can lead to the loss of their axisymmetric shape and to the formation of attached cyclonic eddies, i.e, to the eddy transformation into a multipole eddy structure and even to the breaking up of an eddy into two or three smaller anticyclones [80]. Since the baroclinic instability of eddies is accompanied by the consumption of the potential energy of the eddy, the thermocline and pycnohalocline in this case can rise upward, thereby changing the conditions for the biota existence.

As the factors determining the Batumi anticyclone formation, various authors considered the anticyclonic vorticity of the wind field, the excess of precipitation over evaporation, the deceleration of topographic waves propagating along the sea perimeter in this area and the merging of several eddies (see review [81] and also [82]). According to the assimilation results of altimetric measurements in the Black Sea circulation model [83], the anticyclonic eddy here is formed mainly in March and exists until the end of October - beginning of November. However, as the analysis of IR-images and visible spectral ranges shows, various eddies (one or several) are observed here in all seasons [84]. The Batumi anticyclone is not stationary. Based on the satellite data analysis, including altimetry, it was found that after formation in the coastal southeastern Black Sea, it moves to the northwest at a velocity of 1-5 cm/s, sometimes reaching the northeastern part of the basin [39]. In this case, the eddy lifetime can reach one year.

The algae development within the Batumi eddy can proceed according to different scenarios, depending on the eddy evolution stage. In the above example, in mid-April - early May 2008, the growth of coccolithophores began in the eddy center (Fig. 13, April 11). In early May, the anticyclone began to expand and capture a large amount of shelf waters in its core (Fig. 13, May 5). 

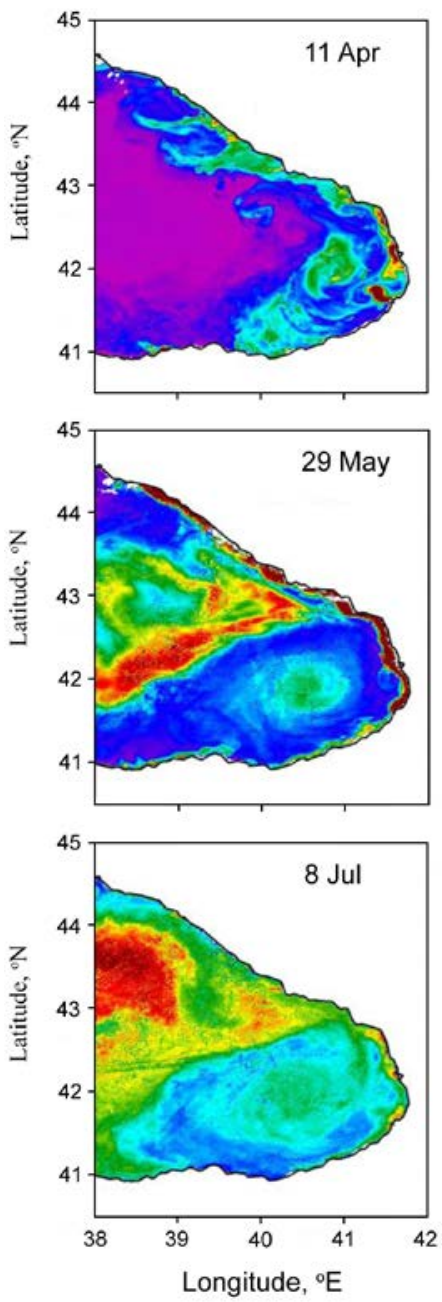
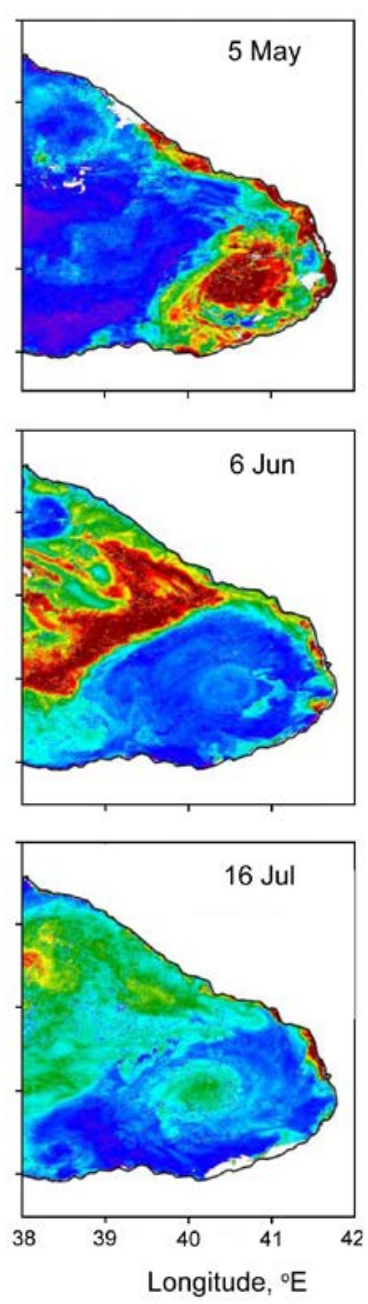
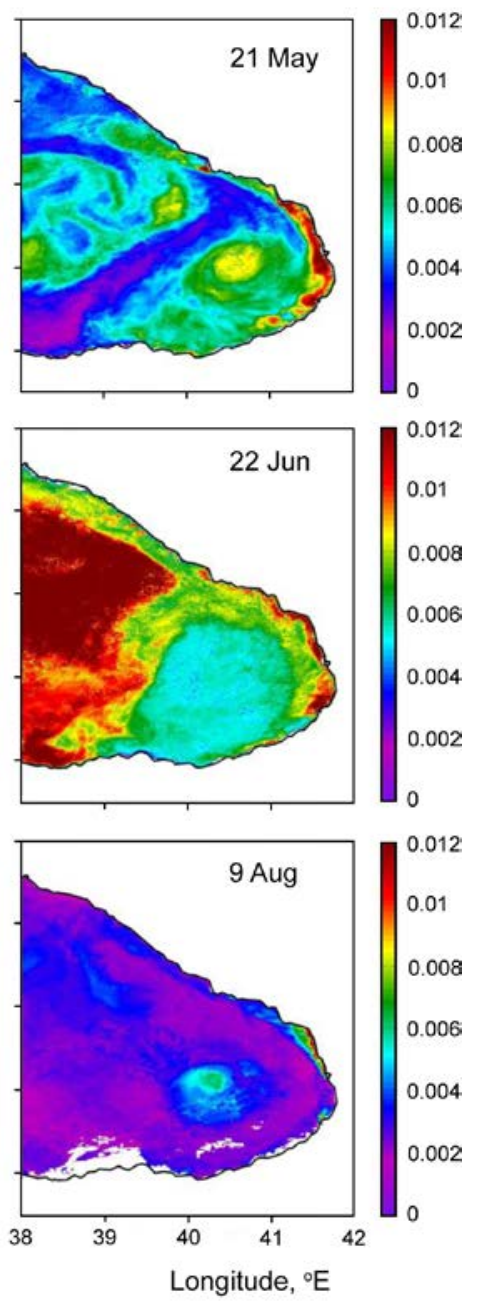

F i g. 13. Evolution of the coccolithophore bloom in the region of the Batumi anticyclone in April August, 2008 based on the RRS measurements

In this area, several rivers flow into the sea, carrying a notable amount of phosphates and nitrates to the shelf [85]. It is possible that the involvement of these fresh waters in the anticyclone leads to an increase in the haline stratification and the formation of a thin UML quickly warmed in the spring with an increased content of nutrients. Note that in the basin southeast during this period the winds are minimal due to the wind shadow of the Caucasus Mountains and the water temperature on the surface reaches the highest values for the sea. It can also be assumed that in this case the anticyclonic circulation was of a lens-like type and was in the stage of water rise in the center, where the UML thickness was minimal. As noted above, this is especially important for the development of such a group of algae as coccolithophores, which have a competitive advantage at high light conditions in this layer [86]. 
As a result, favorable conditions for the coccolithophore bloom appeared in the anticyclone center. At the beginning of May 2008, there was a zone of maximum RRS values - over 0.012. At the same time, the bloom in the surrounding waters had not begun yet and values were less than 0.005 . Much later, in two weeks, by May 21, the RRS in the sea center reached high values as in the Batumi anticyclone (0.009). At the end of May, the bloom of coccolithophores already occupied the central part of the basin, but was absent on the continental slope.

In the anticyclone itself, the bloom began to fade, in June the values decreased and were much lower than outside the eddy. In addition, in late May - early June, the eddy involved in its orbital movements the continental slope waters poor in coccolithophores. As a result, the RRS at the northern periphery of the eddy decreased to background values (Fig. 13, May 29 and June 6). Further, on the entire periphery of the anticyclone, a zone with a minimum RRS was formed, which surrounded the core of the eddy, where the development of coccolithophores was still observed. Note that in the surrounding waters, the strongest bloom is often observed at the eddy front, which is possibly associated with frontal processes (see Section 2.1). By early June, the bloom in the anticyclone center had almost disappeared. At the same time, it continued to develop in the surrounding waters and reached its maximum by the end of June (Fig. 13, June 22). At this time, the Batumi eddy looked like an oval area with the lowest RRS values.

It is characteristic that an area with an increased number of coccolithophores was almost constantly present in the anticyclone core. The question of the reasons for such a long development of these algae remains open. Perhaps this is due to the eddy lens-likeness and the shallow UML in its center. It is the eddy center where nutrients could most actively penetrate into the UML during wind mixing. It is possible that the constant involvement of shelf waters (mainly in the thermocline layer) also played a role, replenishing the supply of nutrients in the eddy center.

As a result, in the second half of July, when the bloom of coccolithophores began to wane in the rest of the sea, the RRS values in the eddy became comparable again to those in the bloom area to the north of it (Fig. 13, July 16). In August, the bloom of coccolithophores was observed only in the core of the Batumi eddy, as in April (Fig. 13, August 9). Thus, in the example above, the bloom of coccolithophores in the Batumi anticyclone began a month earlier than in the surrounding waters, and ended also a month earlier, and then developed again and lasted until the latest time.

It is generally clear that the effect of eddies on the biota largely depends on the time of their existence and on the stage of development. From theoretical concepts it follows that, for example, a cyclonic eddy in the stage of active development increases biological productivity, and at the stage of attenuation, on the contrary, contributes to its decrease [3]. A conceptual model was proposed to describe the fundamental effect of cyclonic and lens-like anticyclonic eddies on plankton [46]. It consisted of seven stages in the eddy's life, including periods of formation, intensification of the vertical flow of nutrients, an increase in primary PHYSICAL OCEANOGRAPHY VOL. 27 ISS. 6 (2020) 
production, export of organic matter from the photic zone, attenuation and disappearance.

Sometimes the dynamics of the eddy's impact is more complex. Thus, 12-year satellite observations of Chl inside 4,564 anticyclonic eddies and 3,675 cyclonic eddies near Eastern Australia at different stages of development showed that the lowest $C h l$ level was observed in the last stage of destruction of anticyclonic eddies [61]. At the same time, Chl near the center of cyclonic eddies decreased from the first to the middle stage, and then increased to a maximum at the last stage. A similar pattern was observed in the anticyclonic eddy near the Gulf Stream [76]. At the initial stage, diatoms dominated in the eddy center, then small phytoflagellates, then again diatoms, but represented by other species.

The influence of duration of the eddy impact on the species composition of planktonic organisms, in contrast to the quantitative level of phytoplankton development, has been very poorly studied. For example, analysis of six different anticyclonic and cyclonic eddies in the Sargasso Sea showed that the phytoplankton structure depended on the eddy age [46]. In young lens-like eddies, phytoplankton consisted of a combination of diatoms, dinoflagellates, prasinophytes and pelagophytes. The older cyclonic eddies were dominated by cyanobacteria.

A few studies on this topic were carried out in the Black Sea. It was shown that short-lived (2-3 weeks) cyclonic eddies increase the phytoplankton biomass, but do not change either the species composition or the dominant species [17]. At the same time, long-lived (several months) eddies fundamentally change the set of dominant species [19]. Moreover, even such long-lived eddies do not have an unambiguous effect on the zooplankton composition [18]. In the southern Atlantic Ocean, the taxonomic composition of phytoplankton in anticyclonic eddies differed depending on their development stage [87]. Small flagellate algae (mainly pelagophytes) dominated in the young eddy; cyanobacteria developed in older anticyclones. To the west of Australia, on the contrary, in the old anticyclonic eddy (78 days), the coccolithophore Emiliania huxleyi prevailed, and in the younger (43 days) cyanobacteria [71]. In the Bay of Biscay, in the center of an anticyclonic lens-like eddy, existing for several months, the diatom Pseudo-nitzschia delicatissima developed in mass at depth, while cyanobacteria dominated in the surrounding waters [62]. Perhaps, the impact of different stages of eddy formations on the species structure of plankton remains the least understood and poorly studied issue.

\section{Conclusion}

The above review of the main mechanisms of the eddy dynamics impact on the planktonic component of marine ecosystems, first of all, shows that these mechanisms are extremely diverse. Moreover, they are not always obvious, especially in the case of anticyclonic eddies, and even more so if a wind or frontal action is superimposed on the eddy dynamics. In addition, long-lived eddies are capable of changing the mechanisms of action on biological organisms as they go 
through different stages of their evolution. At the same time, almost all options for impact in various areas of the World Ocean in one way or another significantly change the biological productivity - as a rule, in a larger direction compared to the surrounding waters.

It should be recognized that, at the level of general indicators of plankton biomass, such as Chl, quite numerous studies generally covered all possible physical mechanisms of action. However, the effect of submesoscale structures generated by mesoscale formations on the biota remains almost unexplored. Another weak point in modern knowledge about the impact of eddy dynamics is the response of the species structure of planktonic communities. As the above review of publications has shown, this reaction is well expressed, but extremely diverse, often contradictory and difficult to analyze. There are almost no studies devoted to the analysis of the factors responsible for the development of certain species. In particular, studies of the role of light in the formation of the species composition of phytoplankton in eddies are completely absent. Note that the species structure is an important link in such a process as the global carbon cycle on the planet. For example, under the dinoflagellates, pico- and nanophytoplankton dominance, carbon is almost not exported from the photic zone. Conversely, the development of diatoms (and especially coccolithophores) in eddies increases the carbon flux to the bottom by orders of magnitude.

An analysis of the research carried out in the world unambiguously confirms the importance of mesoscale eddy processes in the primary production formation in the seas and oceans. This is especially true for such closed seas as the Black Sea, where the eddy dynamics cover a significant water area throughout almost the entire year. It can be clearly stated that, for example, mathematical modeling that do not take into account eddy effects on the biota are doomed to reproduce only extremely generalized models of the functioning of marine ecosystems, which hardly make it possible to study and correctly predict their response to anthropogenic stress and climatic changes. However, the current level of knowledge does not allow full parametrization of even the simplest single eddy impact on plankton. Consequently, studies of the impact of eddy dynamics on biota can and should become part of the global strategy for ocean research in the coming years, announced by the UN as the Decade of Ocean Sciences.

\section{REFERENCES}

1. Falkowski, P., Ziemann, D., Kolber, Z. and Bienfang, P.K., 1991. Role of Eddy Pumping in Enhancing Primary Production in the Ocean. Nature, 352(6330), pp.55-58. https://doi.org/10.1038/352055a0

2. McGillicuddy Jr., D.J., Robinson, A.R., Siegel, D.A., Jannasch, H.W., Johnson, R., Dickey, T.D., McNeil, J., Michaels, A.F. and Knap, A.H., 1998. Influence of Mesoscale Eddies on New Production in the Sargasso Sea. Nature, 394(6690), pp. 263-266. https://doi.org/10.1038/28367

3. McGillicuddy Jr., D.J., 2016. Mechanisms of Physical-Biological-Biogeochemical Interaction at the Oceanic Mesoscale. Annual Review of Marine Science, 8, p. 125-159. https://doi.org/10.1146/annurev-marine-010814-015606 
4. Oguz, T., Macias, D. and Tintore, J., 2015. Ageostrophic Frontal Processes Controlling Phytoplankton Production in the Catalano-Balearic Sea (Western Mediterranean). PLoS One, 10(6), e0129045. doi:10.1371/journal.pone.0129045

5. Levy, M., Klein, P. and Treguier, A.-M., 2001. Impact of Sub-Mesoscale Physics on Production and Subduction of Phytoplankton in an Oligotrophic Regime. Journal of Marine Research, 59(4), pp. 535-565. Available at: https://archimer.ifremer.fr/doc/00000/800/ [Accessed: 05.10.2020].

6. Mahadevan, A., 2016. The Impact of Submesoscale Physics on Primary Productivity of Plankton. Annual Review of Marine Science, 8, pp. 161-184. https://doi.org/10.1146/annurev-marine-010814-015912

7. Zatsepin, A., Kubryakov, A., Aleskerova, A., Elkin, D. and Kukleva, O., 2019. Physical Mechanisms of Submesoscale Eddies Generation: Evidences from Laboratory Modeling and Satellite Data in the Black Sea. Ocean Dynamics, 69(2), pp. 253-266. https://doi.org/10.1007/s10236-018-1239-4

8. $\quad$ Brown, S.L., Landry, M.R., Selph, K.E., Yang, E.J., Rii, Y.M. and Bidigare, R.R., 2008. Diatoms in the Desert: Plankton Community Response to a Mesoscale Eddy in the Subtropical North Pacific. Deep Sea Research Part II: Topical Studies in Oceanography, 55(10-13), pp. 1321-1333. https://doi.org/10.1016/j.dsr2.2008.02.012

9. Oguz, T., Deshpande, A.G. and Malanotte-Rizzoli, P., 2002. The Role of Mesoscale Processes Controlling Biological Variability in the Black Sea Coastal Waters: Inferences from SeaWIFS-Derived Surface Chlorophyll Field. Continental Shelf Research, 22(10), pp. 1477-1492. https://doi.org/10.1016/S0278-4343(02)00018-3

10. Moore, T.S., Matear, R.J., Marra, J. and Clementson, L., 2007. Phytoplankton Variability off the Western Australian Coast: Mesoscale Eddies and Their Role in Cross-Shelf Exchange. Deep Sea Research Part II: Topical Studies in Oceanography, 54(8-10), pp. 943-960. https://doi.org/10.1016/j.dsr2.2007.02.006

11. Kubryakov, A.A., Stanichny, S.V., Zatsepin, A.G. and Kremenetskiy, V.V., 2016. LongTerm Variations of the Black Sea Dynamics and Their Impact on the Marine Ecosystem. Journal of Marine Systems, 163, pp. https://doi.org/10.1016/j.jmarsys.2016.06.006

12. Lima, I.D., Olson, D.B. and Doney, S.C., 2002. Biological Response to Frontal Dynamics and Mesoscale Variability in Oligotrophic Environments: Biological Production and Community Structure. Journal of Geophysical Research: Oceans, 107(C8), 3111. https://doi.org/10.1029/2000JC000393

13. Goldman, J.C. and McGillicuddy Jr., D.J., 2003. Effect of Large Marine Diatoms Growing at Low Light on Episodic New Production. Limnology and Oceanography, 48(3), pp. 1176-1182. https://doi.org/10.4319/lo.2003.48.3.1176

14. Reul, A., Rodríguez, V., Jiménez-Gómez, F., Blanco, J.M., Bautista, B., Sarhan, T., Guerrero, F., Ruíz, J. and García-Lafuente, J., 2005. Variability in the Spatio-Temporal Distribution and Size-Structure of Phytoplankton across an Upwelling Area in the NWAlboran Sea, (W-Mediterranean). Continental Shelf Research, 25(5-6), pp. 589-608. https://doi.org/10.1016/j.csr.2004.09.016

15. Hanson, C.E., Pattiaratchi, C.B. and Waite, A.M., 2005. Sporadic Upwelling on a Downwelling Coast: Phytoplankton Responses to Spatially Variable Nutrient Dynamics off the Gascoyne Region of Western Australia. Continental Shelf Research, 25(12-13), pp. 1561-1582. https://doi.org/10.1016/j.csr.2005.04.003

16. Kahru, M., Mitchell, B.G., Gille, S.T., Hewes, C.D. and Holm-Hansen, O., 2007. Eddies Enhance Biological Production in the Weddell-Scotia Confluence of the Southern Ocean. Geophysical Research Letters, 34(14), L14603. https://doi.org/10.1029/2007GL030430

17. Mikaelyan, A.S., Mosharov, S.A., Kubryakov, A.A., Pautova, L.A., Fedorov, A. and Chasovnikov, V.K., 2020. The Impact of Physical Processes on Taxonomic 
Composition, Distribution and Growth of Phytoplankton in the Open Black Sea. Journal of Marine Systems, 208, 103368. https://doi.org/10.1016/j.jmarsys.2020.103368

18. Arashkevich, E.G., Drits, A.V., Musaeva, E.I., Gagarin, V.I. and Sorokin, P.Yu., 2002. Mesozooplankton Spatial Distribution in Relation to Circulation Pattern in the NorthEastern Part of the Black Sea. In: A. G. Zatsepin and M. V. Flint, Eds., 2002. Multidisciplinary Investigations of the Northeast Part of the Black Sea. Moscow: Nauka, pp. 257-271 (in Russian).

19. Mikaelyan, A.S., Belyaeva, G.A., Georgieva, L.V., Zavyalova, T.A. and Senichkina, L.G., 2002. Influence of Mesoscale Dynamics on the Black Sea Phytoplankton Communities. In: A. G. Zatsepin and M. V. Flint, Eds., 2002. Multidisciplinary Investigations of the Northeast Part of the Black Sea. Moscow: Nauka, pp. 248-257 (in Russian).

20. Lévy, M., Jahn, O., Dutkiewicz, S., Follows, M.J., 2014. Phytoplankton Diversity and Community Structure Affected by Oceanic Dispersal and Mesoscale Turbulence. Limnology and Oceanography: Fluids and Environments, 4(1), pp.67-84. https://doi.org/10.1215/21573689-2768549

21. Field, C.B., Behrenfeld, M.J., Randerson, J.T. and Falkowski, P., 1998. Primary Production of the Biosphere: Integrating Terrestrial and Oceanic Components. Science, 281(5374), pp. 237-240. doi:10.1126/science.281.5374.237

22. Siegel, D.A., McGillicuddy Jr., D.J. and Fields, E.A., 1999. Mesoscale Eddies, Satellite Altimetry, and New Production in the Sargasso Sea. Journal of Geophysical Research: Oceans, 104(C6), pp. 13359-13379. https://doi.org/10.1029/1999JC900051

23. Latun, V.S., 1989. [Role of Anticyclonic Eddies in Intra-Seasonal Evolution of Thermohaline Structure and Geostrophic Circulation]. In: S. P. Levikov, ed., 1989. [Study and Simulation of Hydrophysical Processes in the Black Sea]. Moscow: Gidrometeoizdat, pp. 40-49 (In Russian).

24. Krivosheya, V.G., Moskalenko, L.M., Ovchinnikov, I.M. and Yakubenko, V.G., 1997. Features of Water Dynamics and Hydrological Structure in the Northeastern Black Sea in Autumn, 1993. Oceanology, 37(3), pp. 321-326.

25. Zatsepin, A.G., Ginzburg, A.I., Evdoshenko, M.A., Kostianoy, A.G., Kremenetskiy, V.V., Krivosheya, V.G., Motyzhov, S.V., Poyarkov, S.G., Poulain, P.-M., Sheremet, N.A., Skirta, A.Yu., Soloviev, D.M., Stanichny, S.V. and Yakubenko, V.G., 2002. Mesoscale Eddies and Horizontal Exchange in the Black Sea. In: A. G. Zatsepin and M. V. Flint, Eds., 2002. Multidisciplinary Investigations of the Northeast Part of the Black Sea. Moscow: Nauka, pp. 55-81 (in Russian).

26. Korotaev, G., Oguz, T., Nikiforov, A. and Koblinsky, C., 2003. Seasonal, Interannual, and Mesoscale Variability of the Black Sea Upper Layer Circulation Derived from Altimeter Data. Journal of Geophysical Research: Oceans, 108(C4), 3122. https://doi.org/10.1029/2002JC001508

27. Kubryakov, A.A. and Stanichny, S.V., 2015. Mesoscale Eddies in the Black Sea from Satellite Altimetry Data. Oceanology, 55(1), pp. 56-67. https://doi.org/10.1134/S0001437015010105

28. Kubryakov, A.A., Stanichny, S.V. and Volkov, D.L., 2017. Quantifying the Impact of Basin Dynamics on the Regional Sea Level Rise in the Black Sea. Ocean Science, 13(3), pp. 443-452. https://doi.org/10.5194/os-13-443-2017

29. Ginzburg, A.I., Kostianoy, A.G., Nezlin, N.P., Soloviev, D.M. and Stanichny, S.V., 2002. Anticyclonic Eddies in the Northwestern Black Sea. Journal of Marine Systems, 32(1-3), pp. 91-106. https://doi.org/10.1016/S0924-7963(02)00035-0

30. Shapiro, G.I., Stanichny, S.V. and Stanychna, R.R., 2010. Anatomy of Shelf-Deep Sea Exchanges by a Mesoscale Eddy in the North West Black Sea as Derived from Remotely 
Sensed Data. Remote Sensing of Environment, 114(4), pp. 867-875. https://doi.org/10.1016/j.rse.2009.11.020

31. Karimova, S., 2012. Spiral Eddies in the Baltic, Black and Caspian Seas as Seen by Satellite Radar Data. Advances in Space Research, 50(8), pp. 1107-1124. https://doi.org/10.1016/j.asr.2011.10.027

32. Kubryakov, A.A., Bagaev, A.V., Stanichny, S.V. and Belokopytov, V.N., 2018. Thermohaline Structure, Transport and Evolution of the Black Sea Eddies from Hydrological and Satellite Data. Progress in Oceanography, 167, p. 44-63. https://doi.org/10.1016/j.pocean.2018.07.007

33. Balch, W.M., Holligan, P.M., Ackleson, S.G. and Voss, K.J., 1991. Biological and Optical Properties of Mesoscale Coccolithophore Blooms in the Gulf of Maine. Limnology and Oceanography, 36(4), pp. 629-643. https://doi.org/10.4319/lo.1991.36.4.0629

34. Cokacar, T., Kubilay, N. and Oguz, T., 2001. Structure of Emiliania Huxleyi Blooms in the Black Sea Surface Waters as Detected by SeaWIFS Imagery. Geophysical Research Letters, 28(24), pp. 4607-4610. https://doi.org/10.1029/2001GL013770

35. Kubryakov, A.A. and Stanichny, S.V., 2011. Mean Dynamic Topography of the Black Sea, Computed from Altimetry, Drifter Measurements and Hydrology Data. Ocean Science, 7(6), pp. 745-753. https://doi.org/10.5194/os-7-745-2011

36. Blatov, A.S., Bulgakov, N.P., Ivanov, V.A., Kosarev, A.N. and Tuzhilkin, V.S., 1984. [Variability of Hydrophysical Fields of the Black Sea]. Leningrad: Gidrometeoizdat, 239 p. Available at: http://ru.b-ok.org/book/2974762/202428 [Accessed: 08.11.2020] (in Russian).

37. Zhurbas, V.M., Zatsepin, A.G., Grigor'eva, Yu.V., Poyarkov, S.G., Eremeev, V.N., Kremenetsky, V.V., Motyzhev, S.V., Stanichny, S.V., Soloviev, D.M. and Poulain, P.M., 2004. Water Circulation and Characteristics of Currents of Different Scales in the Upper Layer of the Black Sea from Drifter Data. Oceanology, 44(1), pp. 30-43.

38. Zatsepin, A.G., Ginzburg, A.I., Kostianoy, A.G., Kremenetskiy, V.V., Krivosheya, V.G., Stanichny, S.V. and Poulain, P.-M., 2003. Observations of Black Sea Mesoscale Eddies and Associated Horizontal Mixing. Journal of Geophysical Research: Oceans, 108(C8), 3246. https://doi.org/10.1029/2002JC001390

39. Kubryakov, A.A. and Stanichny, S.V., 2015. Seasonal and Interannual Variability of the Black Sea Eddies and its Dependence on Characteristics of the Large-Scale Circulation. Deep Sea Research Part I: Oceanographic Research Papers, 97, pp. 80-91. https://doi.org/10.1016/j.dsr.2014.12.002

40. Stanev, E.V., 1990. On the Mechanisms of the Black Sea Circulation. Earth-Science Reviews, 28(4), pp. 285-319. https://doi.org/10.1016/0012-8252(90)90052-W

41. Oguz, T., Latun, V.S., Latif, M.A., Vladimirov, V.V., Sur, H.I., Markov, A.A., Özsoy, E., Kotovshchikov, B.B., Eremeev, V.V. and Ünlüata, Ü., 1993. Circulation in the Surface and Intermediate Layers of the Black Sea. Deep Sea Research Part I: Oceanographic Research Papers, 40(8), pp. 1597-1612. https://doi.org/10.1016/09670637(93)90018-X

42. Oguz, T., Aubrey, D.G., Latun, V.S., Demirov, E., Koveshnikov, L., Sur, H.I., Diaconu, V., Besiktepe, S., Duman, M., Limeburner, R. and Eremeev, V., 1994. Mesoscale Circulation and Thermohaline Structure of the Black Sea Observed during HydroBlack '91. Deep Sea Research Part I: Oceanographic Research Papers, 41(4), pp. 603-628. https://doi.org/10.1016/0967-0637(94)90045-0

43. Korotaev, G., Oguz, T. and Riser, S., 2006. Intermediate and Deep Currents of the Black Sea Obtained from Autonomous Profiling Floats. Deep Sea Research Part II: Topical Studies in Oceanography, 53(17-19), pp. 1901-1910. https://doi.org/10.1016/j.dsr2.2006.04.017 
44. Filyushkin, B.N., Lebedev, K.V. and Kozhelupova, N.G., 2017. Detection of Intermediate Mediterranean Waters in the Atlantic Ocean by ARGO Floats Data. Oceanology, 57(6), pp. 763-771. https://doi.org/10.1134/S0001437017060042.

45. Worthington, L.V., 1968. Genesis and Evolution of Water Masses. In: J. M. Mitchell, ed., 1968. Causes of Climatic Change. Boston, MA: American Meteorological Society, pp. 63-67.

46. Sweeney, E.N., McGillicuddy Jr., D.J. and Buesseler, K.O., 2003. Biogeochemical Impacts due to Mesoscale Eddy Activity in the Sargasso Sea as Measured at the Bermuda Atlantic Time-Series Study (BATS). Deep Sea Research Part II: Topical Studies in Oceanography, 50(22-26), pp. 3017-3039. https://doi.org/10.1016/j.dsr2.2003.07.008

47. Zatsepin, A.G., Denisov, E.S., Emel'yanov, S.V., Kremenetskiy, V.V., Poyarkov, S.G., Stroganov, O.Yu., Stanichnaya, R.R. and Stanichny, S.V., 2005. Effect of Bottom Slope and Wind on the Near-Shore Current in a Rotating Stratified Fluid: Laboratory Modeling for the Black Sea. Oceanology, 45(suppl. 1), pp. S13-S26.

48. Ginzburg, A.I., 1994. Horizontal Exchange Processes in the Near-Surface Layer of the Black Sea. Issledovanie Zemli iz Kosmosa, (2), pp. 75-83 (in Russian).

49. Ginzburg, A.I., Zatsepin, A.G., Kostianoy, A.G., Krivosheya, V.G., Poyarkov, S.G., Skirta, A.Yu., Soloviev, D.M., Stanichny, S.V. and Yakubenko, V.G., 2002. Separation of Near-Shore Anticyclonic Eddies from the Caucasian Coast and Their Transformation into Deep-Sea Eddies. In: M. V. Flint and A. G. Zatsepin, Eds., 2002. Multidisciplinary Investigations of the Northeast Part of the Black Sea. Moscow: Nauka, pp. 82-91 (in Russian).

50. Zatsepin, A.G., Kremenetskiy, V.V., Stanichny, S.V. and Burdyugov, V.M., 2010. Black Sea Basin-Scale Circulation and Mesoscale Dynamics under Wind Forcing. In: A. V. Frolov and Yu. D. Resnyansky, Eds., 2010. Modern Problems of Ocean and Atmosphere Dynamics: The Pavel S. Lineykin memorial volume. Moscow: Triada, pp. 347368 (in Russian).

51. He, Q., Zhan, H., Cai, S. and Li, Z., 2016. Eddy Effects on Surface Chlorophyll in the Northern South China Sea: Mechanism Investigation and Temporal Variability Analysis. Deep Sea Research Part I: Oceanographic Research Papers, 112, pp. 25-36. http://dx.doi.org/10.1016/j.dsr.2016.03.004

52. Chen, Y.-L.L., Chen, H.-Y., Lin, I.-I., Lee, M.-A. and Chang, J., 2007. Effects of Cold Eddy on Phytoplankton Production and Assemblages in Luzon Strait bordering the South China Sea. Journal of Oceanography, 63(4), pp. 671-683. https://doi.org/10.1007/s10872-007-0059-9

53. Allen, C.B., Kanda, J. and Laws, E.A., 1996. New Production and Photosynthetic Rates within and outside a Cyclonic Mesoscale Eddy in the North Pacific Subtropical Gyre. Deep Sea Research Part I: Oceanographic Research Papers, 43(6), pp. 917-936. https://doi.org/10.1016/0967-0637(96)00022-2

54. Vaillancourt, R.D., Marra, J., Seki, M.P., Parsons, M.L. and Bidigare, R.R., 2003. Impact of a Cyclonic Eddy on Phytoplankton Community Structure and Photosynthetic Competency in the Subtropical North Pacific Ocean. Deep Sea Research Part I: Oceanographic Research Papers, 50(7), pp. 829-847. https://doi.org/10.1016/S09670637(03)00059-1

55. Mcgillicuddy Jr., D.J., Anderson, L.A., Bates, N.R., Bibby, T., Buesseler, K.O., Carlson, C.A., Davis, C.S., Ewart, C., Falkowski, P.G. [et al.], 2007. Eddy/Wind Interactions Stimulate Extraordinary Mid-Ocean Plankton Blooms. Science, 316(5827), pp. 10211026. doi:10.1126/science.1136256

56. Benitez-Nelson, C.R., Bidigare, R.R., Dickey, T.D., Landry, M.R., Leonard, C.L., Brown, S.L., Nencioli, F., Rii, Y.M., Maiti, K. [et al.] 2007. Mesoscale Eddies Drive 
Increased Silica Export in the Subtropical Pacific Ocean. Science, 316(5827), pp. 10171021. doi:10.1126/science.1136221

57. Olaizola, M., Ziemann, D.A., Bienfang, P.K., Walsh, W.A. and Conquest, L.D., 1993. Eddy-Induced Oscillations of the Pycnocline Affect the Floristic Composition and Depth Distribution of Phytoplankton in the Subtropical Pacific. Marine Biology, 116(4), pp. 533-542. https://doi.org/10.1007/BF00355471

58. Bibby, T.S. and Moore, C.M., 2011. Silicate: Nitrate Ratios of Upwelled Waters Control the Phytoplankton Community Sustained by Mesoscale Eddies in Sub-Tropical North Atlantic and Pacific. Biogeosciences, 8(3), pp. 657-666. https://doi.org/10.5194/bg-8657-2011

59. Sur, H.I. and Ilyin, Yu.P., 1997. Evolution of Satellite Derived Mesoscale Thermal Patterns in the Black Sea. Progress in Oceanography, 39(2), pp.109-151. https://doi.org/10.1016/S0079-6611(97)00009-8

60. Kubryakov, A.A., Zatsepin, A.G. and Stanichny, S.V., 2019. Anomalous SummerAutumn Phytoplankton Bloom in 2015 in the Black Sea Caused by Several Strong Wind Events. Journal of Marine Systems, 194, pp. 11-24. https://doi.org/10.1016/j.jmarsys.2019.02.004

61. Liu, F., Yin, K., He, L., Tang, S. and Yao, J., 2018. Influence on Phytoplankton of Different Developmental Stages of Mesoscale Eddies off Eastern Australia. Journal of Sea Research, 137, pp. 1-8. https://doi.org/10.1016/j.seares.2018.03.004

62. Rodríguez, F., Varela, M., Fernández, E. and Zapata, M., 2003. Phytoplankton and Pigment Distributions in an Anticyclonic Slope Water Oceanic Eddy (SWODDY) in the Southern Bay of Biscay. Marine Biology, 143(5), pp. 995-1011. https://doi.org/10.1007/s00227-003-1129-1

63. Jeffrey, S.W. and Hallegraeff, G.M., 1980. Studies of Phytoplankton Species and Photosynthetic Pigments in a Warm Core Eddy of the East Australian Current. I. Summer Populations. Marine Ecology Progress Series, 3(4), pp. 285-294. doi:10.3354/meps003285

64. Zatsepin, A.G., Ostrovskii, A.G., Kremenetskiy, V.V., Piotukh, V.B., Kuklev, S.B., Moskalenko, L.V., Podymov, O.I., Baranov, V.I., Korzh, A.O. and Stanichny, S.V., 2013. On the Nature of Short-Period Oscillations of the Main Black Sea Pycnocline, Submesoscale Eddies, and Response of the Marine Environment to the Catastrophic Shower of 2012. Izvestiya, Atmospheric and Oceanic Physics, 49(6), pp. 659-673. https://doi.org/10.1134/S0001433813060145

65. De Souza, R.B., Mata, M.M., Garcia, C.A.E., Kampel, M., Oliveira, E.N. and Lorenzzetti, J.A., 2006. Multi-Sensor Satellite and In Situ Measurements of a Warm Core Ocean Eddy South of the Brazil-Malvinas Confluence Region. Remote Sensing of Environment, 100(1), pp. 52-66. https://doi.org/10.1016/j.rse.2005.09.018

66. Baltar, F., Arístegui, J., Gasol, J.M., Lekunberri, I. and Herndl, G.J., 2010. Mesoscale Eddies: Hotspots of Prokaryotic Activity and Differential Community Structure in the Ocean. The ISME Journal, 4(8), pp. 975-988. https://doi.org/10.1038/ismej.2010.33

67. Paterson, H.L., Knott, B. and Waite, A.M., 2007. Microzooplankton Community Structure and Grazing on Phytoplankton, in an Eddy Pair in the Indian Ocean off Western Australia. Deep Sea Research Part II: Topical Studies in Oceanography, 54(810), pp. 1076-1093. https://doi.org/10.1016/j.dsr2.2006.12.011

68. Lehahn, Y., d'Ovidio, F., Lévy, M. and Heifetz, E., 2007. Stirring of the Northeast Atlantic Spring Bloom: A Lagrangian Analysis Based on Multisatellite Data. Journal of Geophysical Research: Oceans, 112(C8), C08005. https://doi.org/10.1029/2006JC003927

69. Zodiatis, G., Drakopoulos, P., Brenner, S. and Groom, S., 2005. Variability of the Cyprus Warm Core Eddy during the CYCLOPS Project. Deep Sea Research Part II: 
Topical Studies in Oceanography, 52(22-23), pp. 2897-2910. https://doi.org/10.1016/j.dsr2.2005.08.020

70. Srokosz, M.A., Martin, A.P. and Fasham, M.J.R., 2003. On the Role of Biological Dynamics in Plankton Patchiness at the Mesoscale: An Example from the Eastern North Atlantic Ocean. Journal of Marine Research, 61(4), pp. 517-537. https://doi.org/10.1357/002224003322384915

71. Huang, B., Hu, J., Xu, H., Cao, Z. and Wang, D., 2010. Phytoplankton Community at Warm Eddies in the Northern South China Sea in Winter 2003/2004. Deep Sea Research Part II: Topical Studies in Oceanography, 57(19-20), pp. 1792-1798. http://dx.doi.org/10.1016/j.dsr2.2010.04.005

72. Batten, S.D. and Crawford, W.R., 2005. The Influence of Coastal Origin Eddies on Oceanic Plankton Distributions in the Eastern Gulf of Alaska. Deep Sea Research Part II: Topical Studies in Oceanography, 52(7-8), pp. 991-1009. https://doi.org/10.1016/j.dsr2.2005.02.009

73. Mackas, D.L. and Galbraith, M.D., 2002. Zooplankton Distribution and Dynamics in a North Pacific Eddy of Coastal Origin: I. Transport and Loss of Continental Margin Species. Journal of Oceanography, 58(5), pp. 725-738. https://doi.org/10.1023/A:1022802625242

74. Kubryakov, A.A., Belokopytov, V.N., Zatsepin, A.G., Stanichny, S.V. and Piotukh, V.B., 2019. The Black Sea Mixed Layer Depth Variability and Its Relation to the Basin Dynamics and Atmospheric Forcing. Physical Oceanography, 26(5), pp. 397-413. doi:10.22449/1573-160X-2019-5-397-413

75. Sverdrup, H.U., 1953. On Conditions for the Vernal Blooming of Phytoplankton. ICES Journal of Marine Science, 18(3), pp. 287-295. https://doi.org/10.1093/icesjms/18.3.287

76. Gould Jr., R.W. and Fryxell, G.A., 1988. Phytoplankton Species Composition and Abundance in a Gulf Stream Warm Core Ring. I. Changes over a Five Month Period. Journal of Marine Research, 46(2), pp. 367-398. https://doi.org/10.1357/002224088785113649

77. Martin, A.P. and Richards, K.J., 2001. Mechanisms for Vertical Nutrient Transport within a North Atlantic Mesoscale Eddy. Deep Sea Research Part II: Topical Studies in Oceanography, 48(4-5), pp. 757-773. https://doi.org/10.1016/S0967-0645(00)00096-5

78. Gaube, P., Chelton, D.B., Strutton, P.G. and Behrenfeld, M.J., 2013. Satellite Observations of Chlorophyll, Phytoplankton Biomass, and Ekman Pumping in Nonlinear Mesoscale Eddies. Journal of Geophysical Research: Oceans, 118(12), pp. 6349-6370. http://dx.doi.org/10.1002/2013jc009027

79. Demyshev, S.G. and Dymova, O.A., 2018. Numerical Analysis of the Black Sea Currents and Mesoscale Eddies in 2006 and 2011. Ocean Dynamics, 68(10), pp. 13351352. https://doi.org/10.1007/s10236-018-1200-6

80. Kostianoy, A.G. and Zatsepin, A.G., 1989. Laboratory Experiments with Baroclinic Vortices in a Rotating Fluid. In: J. C. J. Nihoul and B. M. Jamart, Eds., 1989. Mesoscale/Synoptic Coherent Structures in Geophysical Turbulence. Amsterdam: Elsevier, pp. 691-700. https://doi.org/10.1016/S0422-9894(08)70215-0

81. Lavrova, O.Yu., Kostianoy, A.G., Lebedev, S.A., Mityagina, V.I., Ginzburg, A.I. and Sheremet, N.A., 2011. Complex Satellite Monitoring of the Russian Seas. Moscow: IKI RAN, 480 p. Available at: http://www.iki.rssi.ru/books/2011monitoring.pdf [Accessed: 01.10.2020] (in Russian).

82. Mityagina, M.I., Lavrova, O.Y., Karimova, S.S., 2010. Multi-Sensor Survey of Seasonal Variability in Coastal Eddy and Internal Wave Signatures in the NorthEastern Black Sea. International Journal of Remote Sensing, 31(17-18), pp. 4779-4790. https://doi.org/10.1080/01431161.2010.485151 
83. Korotaev, G.K., Oguz, T., Nikiforov, A.A., Beckley, B.D. and Koblinskij, C.J., 2002. Dynamics of the Black Sea anticyclones derived from Spacecraft Remote Sensing Altimetry. Issledovanie Zemli iz Kosmosa, (6), pp. 60-70 (in Russian).

84. Kubryakov, A.A. and Stanichny, S.V., 2015. Dynamics of Batumi Anticyclone from the Satellite Measurements. Physical Oceanography, (2), pp. 59-68. doi:10.22449/1573-160X-2015-2-59-68

85. Zavialov, P.O., Makkaveev, P.N., Konovalov, B.V., Osadchiev, A.A., Khlebopashev, P.V., Pelevin, V.V., Grabovskiy, A.B., Izhitskiy, A.S., Goncharenko, I.V., Soloviev, D.M. and Polukhin, A.A., 2014. Hydrophysical and Hydrochemical Characteristics of the Sea Areas Adjacent to the Estuaries of Small Rivers of the Russian Coast of the Black Sea. Oceanology, 54(3), pp. 265-280. https://doi.org/10.1134/S0001437014030151

86. Paasche, E., 2001. A Review of the Coccolithophorid Emiliania Huxleyi (Prymnesiophyceae), with Particular Reference to Growth, Coccolith Formation, and Calcification-Photosynthesis Interactions. Phycologia, 40(6), pp. 503-529. https://doi.org/10.2216/i0031-8884-40-6-503.1

87. Carvalho, A.D.C.D.O., Mendes, C.R.B., Kerr, R., Azevedo, J.L.L., Galdino, F. and Tavano, V.M., 2019. The Impact of Mesoscale Eddies on the Phytoplankton Community in the South Atlantic Ocean: HPLC-CHEMTAX Approach. Marine Environmental Research, 144, pp. 154-165. https://doi.org/10.1016/j.marenvres.2018.12.003

About the authors:

Aleksandr S. Mikaelyan, Leading Research Associate, IO RAS (36 Nahimovskiy pr., Moscow, 117997, Russia), Dr. Sci. (Biol.)

Andrey G. Zatsepin, head of laboratory, IO RAS (36 Nahimovskiy pr., Moscow, 117997, Russia), Dr. Sci. (Math.-Phys.), ORCID ID: 0000-0002-5527-5234, zatsepin@ocean.ru

Arseniy A. Kubryakov, Senior Research Associate, Marine Hydrophysical Institute of RAS (2 Kapitanskaya, Sevastopol, 299011, Russia), Ph. D (Math.-Phys.), ORCID ID: 0000-0003-3561-5913, arskubr@mhiras.ru

Contribution of the co-authors:

Alexander Mikaelyan - conceptualization; supervision; review of biological responses; writing - original draft; funding acquisition

Andrey Zatsepin - theoretical considerations, shemes, illustrations, review and editing

Arseny Kubryakov - methodology; satellite imaginery; illustrations, review and editing

All the authors have read and approved the final manuscript.

The authors declare that they have no conflict of interest. 